\title{
Direito à informação em saúde: uma revisão integrativa
}

\author{
Right to health information: an integrative review
}

Derecho a la información en salud: una revisión integrativa

\author{
Renata Leite ${ }^{1}$ \\ Carla Ventura ${ }^{2}$ \\ Bruna Carrara ${ }^{3}$
}

Resumo. Objetivo: Identificar, avaliar criticamente e sintetizar as evidências científicas relacionadas ao conhecimento de profissionais de saúde e usuários sobre direito à informação em saúde. Metodologia: Revisão integrativa da literatura. Foram selecionadas as bases de dados Hein Online, ISTA, Lilacs, LISA, PubMed e Web of Science para a identificação de estudos primários. Resultados: Um total de 6888 estudos foi identificado e, considerando os critérios de seleção, 15 estudos primários foram incluídos na revisão. As categorias temáticas desta revisão foram agrupadas de acordo com o conhecimento dos usuários sobre seu direito à informação e conhecimento dos profissionais sobre o direito à informação do usuário. Conclusões: Verifica-se a necessidade de capacitação de profissionais de saúde em relação ao direito dos usuários de serviços de saúde. Assim, a educação dos profissionais mostra-se como uma possibilidade de se fazer cumprir o direito à informação do paciente, melhorando a prática assistencial e, consequentemente, as condições de saúde das pessoas e o exercício de seus direitos.

Palavras-chave: Direito à saúde. Acesso à Informação. Comunicação em Saúde

\begin{abstract}
Objective: To identify, critically evaluate and synthesize the scientific evidence related to the knowledge of health professionals and users about the right to health information. Methodology: Integrative literature review with the goal The databases Hein Online, ISTA, Lilacs, LISA, PubMed and Web of Science were selected for the identification of primary studies. Results: A total of 6888 studies were identified and, considering the selection criteria, 15 primary studies were included in the review. The thematic categories of this review were grouped according to the users' knowledge about their right to information and knowledge of the professionals about the right to information of the user. Conclusions: There is a need to train health professionals in relation to the right of health service users. Thus, the education of professionals is considered a possibility to enforce the right to information of the patient, improving the practice of care and, consequently, the health conditions of people and the exercise of their rights.
\end{abstract}

Keywords: Right to health. Access to Information. Health Communication

Resumén. Objetivo: Identificar, evaluar críticamente y sintetizar las evidencias científicas relacionadas al conocimiento de profesionales de salud y usuarios sobre derecho a la información en salud. Metodología: Revisión integrativa de la literatura. Se seleccionaron

\footnotetext{
${ }^{1}$ Escola de Enfermagem de Ribeirão Preto, Universidade de São Paulo. E-mail: rafigleite@gmail.com

2 Escola de Enfermagem de Ribeirão Preto, Universidade de São Paulo. E-mail: caaventu@eerp.usp.br

${ }^{3}$ Escola de Enfermagem de Ribeirão Preto, Universidade de São Paulo. E-mail: brunasordi.c@hotmail.com
} 
las bases de datos Hein Online, ISTA, Lilacs, LISA, PubMed y Web of Science para la identificación de estudios primarios. Resultados: Un total de 6888 estudios fue identificado y, considerando los criterios de selección, 15 estudios primarios fueron incluidos en la revisión. Las categorías temáticas de esta revisión fueron agrupadas de acuerdo con el conocimiento de los usuarios sobre su derecho a la información y conocimiento de los profesionales sobre el derecho a la información del usuario. Conclusiones: Se verifica la necesidad de capacitación de profesionales de salud en relación al derecho de los usuarios de servicios de salud. Así, la educación de los profesionales se muestra como una posibilidad de hacer cumplir el derecho a la información del paciente, mejorando la práctica asistencial y, consecuentemente, las condiciones de salud de las personas y el ejercicio de sus derechos.

Palabras-Ilave: Derecho a la Salud. Acceso a la Información. Comunicación en Salud

\section{Introdução}

Os direitos do homem se referem aos valores éticos-políticos, ao direito natural e aos direitos de liberdade que decorrem dele. Não são propriamente direitos, mas algo que surge antes deles e como fundamento deles. Os direitos do homem são a matéria prima dos direitos fundamentais, ou ainda, os direitos fundamentais são os direitos do homem positivados (1). Dentre os direitos fundamentais, ressaltam-se os direitos sociais, prestações positivas proporcionadas pelo Estado direta ou indiretamente, contidas em normas constitucionais e que possibilitam melhores condições de vida aos mais fracos. São direitos que se ligam ao direito de igualdade (2).

O direito à saúde faz parte do conjunto de direitos mais difíceis de serem protegidos, se comparado aos direitos civis e políticos (3). O direito à saúde, como direito fundamental e também social, insere-se neste contexto como eixo norteador para o direito à informação em saúde, no qual todo usuário de serviços de saúde tem direito a receber informações relevantes sobre sua saúde, tratamentos médicos e serviços de saúde (2).

Para usuários de serviços de saúde, pode ser natural receber determinadas informações, como resultados de exames, orientações sobre medicamentos, precisando de menos explicações. Porém, alguns usuários necessitam de explicações mais detalhadas, dependendo do grau de instrução. A informação, quando mediada pelo profissional de saúde, necessita da adequação à pessoa, uma vez que a informação que um indivíduo necessita pode não ser entendida por outro da mesma maneira. Assim, o usuário ressignifica a informação, sintetizando-a e contextualizando-a em sua vivência (4).

Portanto, não basta enviar informações para comunicar, sendo que a comunicação só se efetiva quando o receptor a "recebe", no sentido pleno do termo, ou seja, quando este 
tem condições para se apropriar desta informação, interiorizá-la e introduzi-la em seu estoque de conhecimentos. Assim como a informação, a comunicação tampouco constrói o conhecimento, e ambas estão submetidas a um conhecimento preliminar do receptor (5).

A informação em saúde transformada em conhecimento dentro de um contexto, pode levar a apropriação da informação pelo usuário, empoderando-o e trazendo possibilidades para que ele exerça efetivamente seu direito à saúde. Este estudo embasa-se na concepção de direito como um processo de construção social e que vai muito além da existência de leis e do monopólio estatal e enfoca os direitos humanos e fundamentais (6).

Justifica-se esta revisão pela necessidade de divulgação entre os profissionais de saúde dos direitos dos usuários à informação sobre todos os aspectos referentes à sua saúde, como diagnóstico detalhado, prognóstico, explicação sobre medicamentos e receitas médicas, tratamento, consentimento informado, confidencialidade, privacidade, acesso ao prontuário em caso de necessidade e qualquer outro tipo de informação referente a saúde do usuário.

Nesse sentido, este trabalho apresenta como objetivos identificar, avaliar criticamente e sintetizar as evidências científicas relacionadas ao conhecimento de profissionais de saúde e usuários sobre direito à informação em saúde.

\section{Método}

Foi realizada revisão integrativa, incluindo estudos experimentais e não-experimentais para melhor compreensão do fenômeno analisado. Foram percorridas seis etapas no processo da revisão: elaboração da pergunta de pesquisa, amostragem/estabelecimento de critérios para inclusão e exclusão de estudos, extração de informações dos estudos incluídos, análise crítica dos estudos incluídos, interpretação e discussão dos resultados e apresentação da revisão integrativa (7).

A revisão foi conduzida a partir da pergunta: Quais são as evidências disponíveis sobre o conhecimento dos profissionais e usuários dos serviços a respeito do direito à informação em saúde? Para a elaboração da pergunta foi utilizada a estratégia PICo ( $P$ : população ou problema; I: fenômeno de interesse; Co: contexto) (8), que consistiu em: P ( usuários/pacientes/clientes); I (direito à informação); Co (direito).

Para o levantamento dos artigos e a realização da revisão integrativa foram realizadas buscas eletrônicas em seis bases de dados: Hein on line (base de dados para 
pesquisa jurídica que contém textos completos de jurisprudência e publicações de direito anglo-saxão), ISTA (Base de dados de Ciência da Informação e Tecnologia), Lilacs (Base de dados de Ciências da saúde latino-americana e do Caribe), Lisa (Base de dados de biblioteconomia, Ciência da Informação e Tecnologia com texto completo), Pubmed (base de dados de Ciências da vida) e Web of Science (base de dados Multidisciplinar).

A busca nas bases de dados Hein, ISTA, Lilacs, LISA, Pubmed e Web of Science resultaram em 6888 estudos primários. Destes, 4036 não contemplavam os critérios de inclusão e exclusão da presente revisão integrativa. Após leitura de títulos e resumos, foram selecionados 202 estudos elegíveis. Destes, 4 eram duplicados e 183 não atendiam a questão norteadora. A Figura 1 descreve o percurso de seleção dos artigos.

Figura 1. Seleção dos estudos identificados nas bases de dados

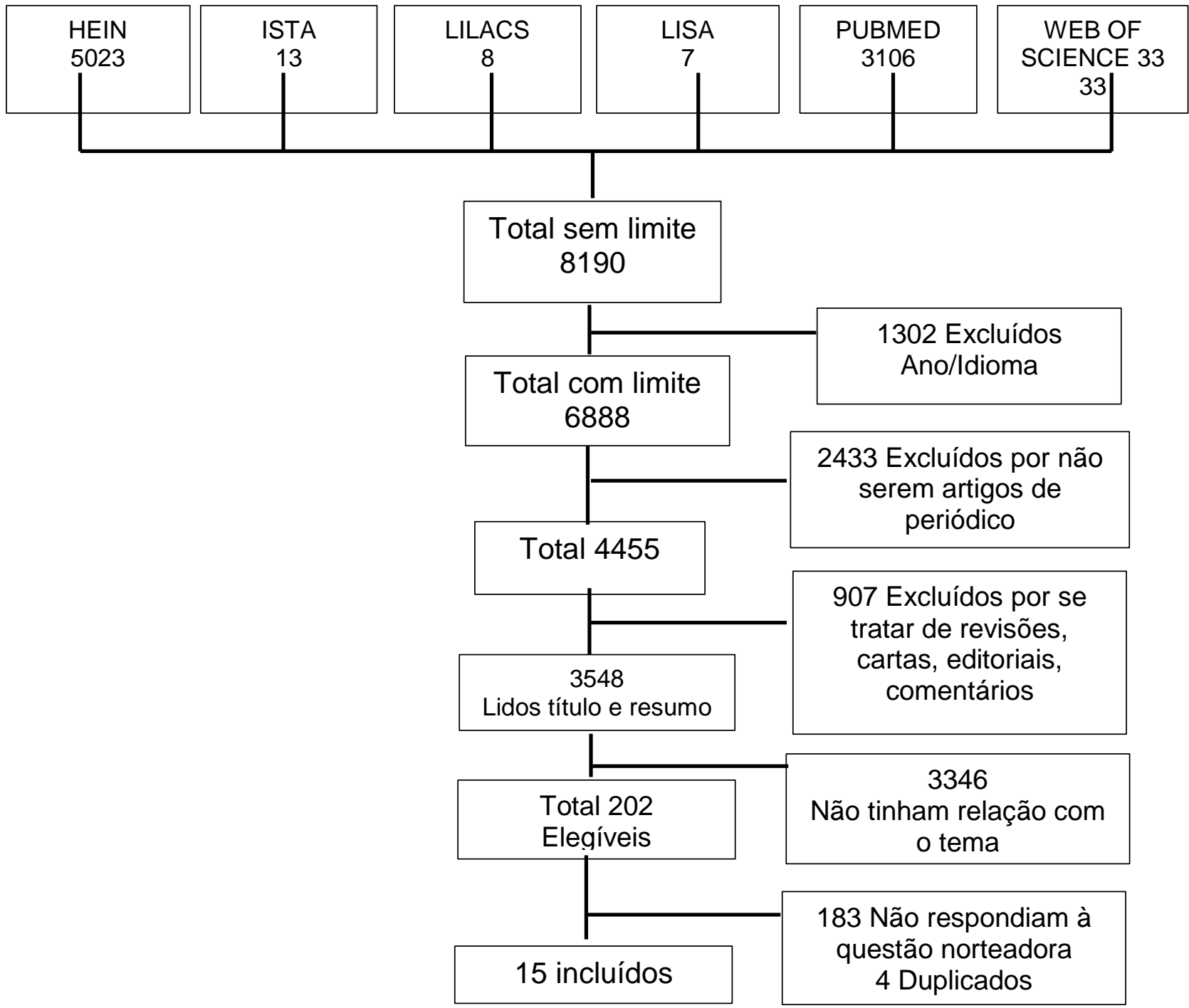


Para a obtenção dos estudos relacionados à temática proposta, a qualificação do processo ocorreu pela busca de descritores por meio do MeSH (Medical Subject Headings) e DeCS (Descritores de Ciências da Saúde). Os vocabulários utilizados foram: "patient(s)", "user(s)", "cliente(s)", "access to information", "health communication", "consumer health information", "right to information", "information rights", patient right(s)", "human right(s)".

Para a seleção dos estudos foi utilizada a questão norteadora e os critérios de seleção adotados nesta revisão. Os estudos elegíveis foram selecionados a partir da leitura criteriosa do título e resumo (quando havia), e ainda de artigos na íntegra caso houvesse necessidade de mais informações.

Os critérios de inclusão da revisão integrativa foram: estudos primários publicados em português, inglês e espanhol; estudos primários disponíveis nas bases de dados no período compreendido entre janeiro de 2005 a novembro de 2014; estudos primários publicados em periódicos, na íntegra, que abordassem o conhecimento dos profissionais e usuários sobre o direito à informação em saúde respondendo à questão norteadora. Os critérios de exclusão adotados foram: estudos secundários (revisão narrativa, revisão de legislação, revisão integrativa, revisão sistemática, cartas e editoriais).

A análise crítica dos estudos exige uma abordagem organizada para ponderar o rigor e as caraterísticas de cada estudo (9). Para a extração das informações dos estudos primários foi utilizado um instrumento para coleta de dados (10). Fundamentando-se nos resultados da avaliação crítica dos estudos incluídos na revisão, foram realizadas comparações e identificadas conclusões e implicações resultantes da revisão (11).

\section{Resultados}

A amostra final foi composta por 15 estudos primários conforme os critérios de seleção propostos. Os estudos identificados como questão clínica de significado e em sua maioria descritivos, foram classificados com nível de evidência IV (12). Os dados dos estudos analisados estão apresentados no Quadro 1, conforme título, autores, periódico e ano de publicação, objetivos, método, resultados e conclusões.

A síntese dos dados, em que são reunidas informações de forma detalhada sobre o direito à informação em saúde, fornece subsídios para que os profissionais de saúde possam aperfeiçoar a comunicação profissional-paciente, além do próprio conhecimento do profissional sobre o direito do usuário sobre seu direito à informação. 
Quadro 1. Identificação, objetivo, método, resultados e conclusões dos estudos analisados

\begin{tabular}{|c|c|c|c|c|c|}
\hline Título & $\begin{array}{c}\text { Autores/ } \\
\text { Periódico/ } \\
\text { Ano }\end{array}$ & Objetivo & Método & Resultados & Conclusões \\
\hline $\begin{array}{l}\text { Patients' } \\
\text { awareness } \\
\text { of their } \\
\text { rights: } \\
\text { insight } \\
\text { from a } \\
\text { developing } \\
\text { country }\end{array}$ & $\begin{array}{l}\text { Mastaneh, Z.; } \\
\text { Mouseli, L. } \\
\text { Int J Health } \\
\text { Policy Manag } \\
2013\end{array}$ & $\begin{array}{l}\text { Avaliar a } \\
\text { consciência } \\
\text { dos } \\
\text { pacientes de } \\
\text { seus direitos } \\
\text { baseados } \\
\text { na Carta de } \\
\text { Direitos dos } \\
\text { Pacientes do } \\
\text { Irã, em dois } \\
\text { hospitais de } \\
\text { ensino } \\
\text { superior } \\
\text { filiados à } \\
\text { Universidade } \\
\text { de Ciências } \\
\text { Médicas } \\
\text { Shiraz no } \\
\text { Irã. }\end{array}$ & $\begin{array}{l}\text { Estudo } \\
\text { descritivo } \\
\text {-analítico- } \\
\text { transvers } \\
\text { al; } \\
\text { Amostra: } \\
200 \\
\text { pacientes } \\
\text { internado } \\
\text { s; } \\
\text { Instrume } \\
\text { nto: } \\
\text { questioná } \\
\text { rio } \\
\text { (escala } \\
\text { Likert). }\end{array}$ & $\begin{array}{l}\text { Em 30,5\% dos } \\
\text { casos, } \\
\text { conscientização d } \\
\text { os pacientes foi } \\
\text { fraca, em } 59,4 \% \\
\text { foi moderada, e } \\
\text { em 10,1\% deles } \\
\text { foi boa. A maior } \\
\text { consciência foi } \\
\text { sobre a confiança } \\
\text { e garantia de } \\
\text { confidencialidade } \\
\text { da equipe de } \\
\text { tratamento, e a } \\
\text { menor foi sobre o } \\
\text { fornecimento de } \\
\text { informações sobre } \\
\text { suficientes sobre } \\
\text { as opções de } \\
\text { tratamento e suas } \\
\text { complicações. Ho } \\
\text { uve uma relação } \\
\text { significativa entre } \\
\text { nível de } \\
\text { escolaridade e o } \\
\text { local a de } \\
\text { residência dos } \\
\text { pacientes } \\
\text { com consciência ( } \\
\text { P <0,001). }\end{array}$ & 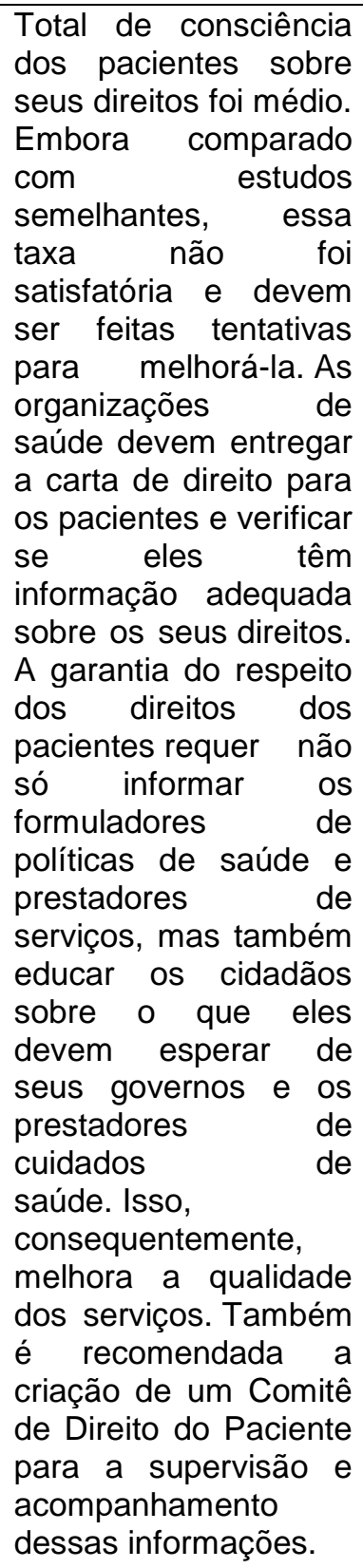 \\
\hline $\begin{array}{l}\text { The } \\
\text { perception } \\
\text { of patients' } \\
\text { rights } \\
\text { among } \\
\text { Belgian } \\
\text { population }\end{array}$ & $\begin{array}{lr}\text { Devroey, } & \text { D.; } \\
\text { Deneyer, } & \text { M.; } \\
\text { Scheys, } & \text { E.; } \\
\text { Van } & \text { De } \\
\text { Vijver, } & \text { E.; } \\
\text { Van } & \text { den } \\
\text { Block, L. } & \end{array}$ & $\begin{array}{l}\text { Explorar } 0 \\
\text { conheciment } \\
\text { orra e } \\
\text { percepção } \\
\text { de } 20 \\
\text { direitos dos } \\
\text { pacientes } \\
\text { específicos e }\end{array}$ & $\begin{array}{l}\text { descritivo } \\
\text { quantitati } \\
\text { vo; } \\
\text { Amostra: } \\
\text { 309 } \\
\text { usuários; }\end{array}$ & \begin{tabular}{|lr} 
Os participantes \\
julgaram direitos \\
dos & pacientes \\
sobre o final da \\
vida & $(88 \%)$, \\
cuidados & de \\
saúde & acessíveis \\
$(87 \%)$ & e
\end{tabular} & $\begin{array}{l}\text { A acessibilidade dos } \\
\text { cuidados de saúde é a } \\
\text { maior preocupação de } \\
\text { todos os participantes. } \\
\text { Isso é notável, } \\
\text { sabendo que a Bélgica } \\
\text { tem um sistema de } \\
\text { seguro de saúde muito }\end{array}$ \\
\hline
\end{tabular}




\begin{tabular}{|c|c|c|c|c|c|}
\hline & $\begin{array}{l}\text { Cent Eur J } \\
\text { Public Health } \\
2013\end{array}$ & $\begin{array}{l}\text { Os } \\
\text { problemas } \\
\text { com seu } \\
\text { cumprimento } \\
\text { entre a } \\
\text { população } \\
\text { belga, } \\
\text { especificame } \\
\text { nte em } \\
\text { relação a } \\
\text { característic } \\
\text { as sócio- } \\
\text { demográfica } \\
\text { s dos } \\
\text { entrevistado } \\
\text { s. }\end{array}$ & $\begin{array}{l}\text { Instrume } \\
\text { nto: } \\
\text { questioná } \\
\text { rio. }\end{array}$ & $\begin{array}{l}\text { informações } \\
\text { sobre estado de } \\
\text { saúde (85\%) } \\
\text { como as questões } \\
\text { mais importantes. } \\
\text { Demonstraram } \\
\text { preocupação em } \\
\text { especial com os } \\
\text { seus direitos } \\
\text { sobre os cuidados } \\
\text { oferecidos na } \\
\text { própria língua dos } \\
\text { pacientes (21\%), } \\
\text { a eutanásia (15\%) } \\
\text { e cuidados de } \\
\text { saúde acessíveis } \\
\text { (14\%). }\end{array}$ & $\begin{array}{l}\text { acessível. } \\
\text { participantes } \\
\text { preocupam-se sobre } \\
\text { cuidados de fim de } \\
\text { vida e cuidados } \\
\text { prestados na própria } \\
\text { língua dos pacientes. } \\
\text { Embora a Bélgica seja } \\
\text { um dos três países do } \\
\text { mundo, com uma lei } \\
\text { que regulamenta } \\
\text { cuidados de fim de } \\
\text { vida e eutanásia, as } \\
\text { pessoas estão } \\
\text { preocupadas sobre a } \\
\text { qualidade do } \\
\text { atendimento durante a } \\
\text { última fase da vida. }\end{array}$ \\
\hline 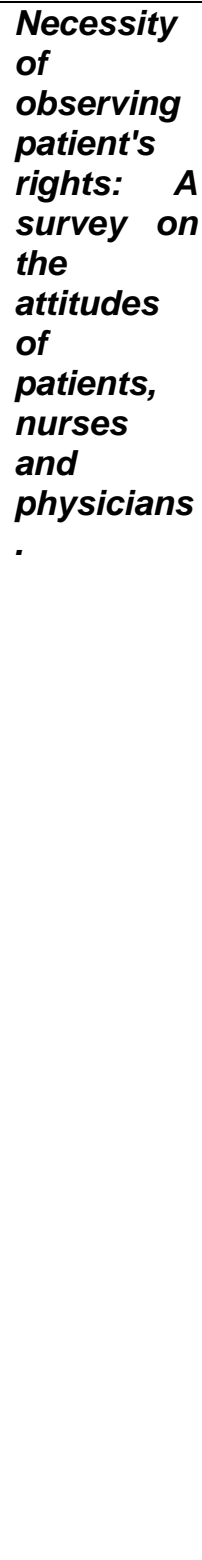 & $\begin{array}{l}\text { Parsapoor, } \\
\text { A., } \\
\text { Mohammad, } \\
\text { K.; Afzali, H.; } \\
\text { Ala'eddini, F.; } \\
\text { Larijani, B. } \\
\text { Journal of } \\
\text { Medical } \\
\text { Ethics and } \\
\text { History of } \\
\text { Medicine } \\
2012\end{array}$ & $\begin{array}{l}\text { Comparar as } \\
\text { atitudes dos } \\
\text { pacientes } \\
\text { como } \\
\text { destinatários } \\
\text { de serviços } \\
\text { de saúde } \\
\text { com a } \\
\text { atitude dos } \\
\text { médicos e } \\
\text { enfermeiros } \\
\text { como depresentant } \\
\text { repres dos } \\
\text { es prestadores } \\
\text { de cuidados } \\
\text { de saúde em } \\
\text { relação à } \\
\text { necessidade } \\
\text { de se } \\
\text { observar } \\
\text { vários } \\
\text { aspectos } \\
\text { dos direitos } \\
\text { dos pacientes, } \\
\text { inclusive } \\
\text { sobre } \\
\text { direito } \\
\text { informação, à } \\
\text { em hospitais } \\
\text { que de } \\
\text { representam } \\
\text { os modelos } \\
\text { de prestação } \\
\text { médico serviço } \\
\text { (ensino, }\end{array}$ & $\begin{array}{l}\text { Estudo } \\
\text { descritivo } \\
\text {-analítico- } \\
\text { transvers } \\
\text { al; } \\
\text { Instrume } \\
\text { nto: } \\
\text { questioná } \\
\text { rio } \\
\text { (escala } \\
\text { Likert); } \\
\text { Amostra: } \\
143 \\
\text { pacientes } \\
\text { enfermeir } \\
\text { os e } 82 \\
\text { médicos. }\end{array}$ & 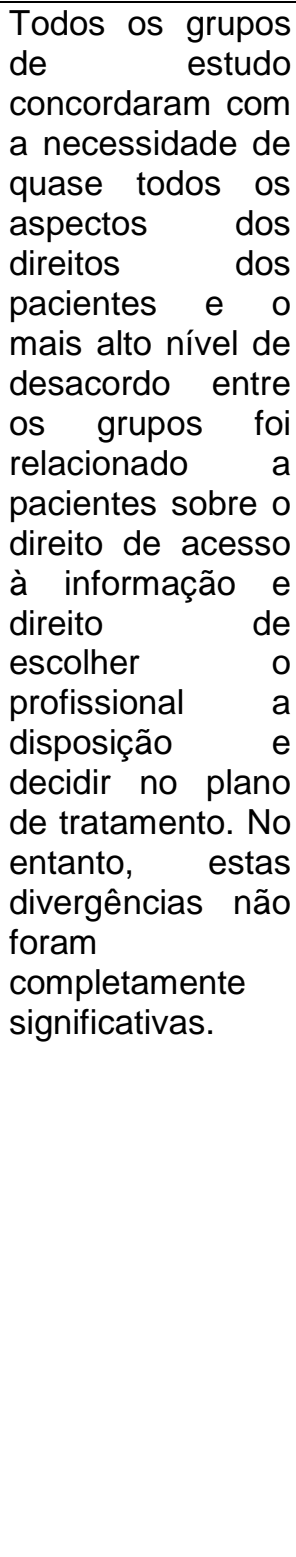 & $\begin{array}{l}\text { De acordo com os } \\
\text { resultados, observa-se } \\
\text { que os profissionais de } \\
\text { saúde, especialmente } \\
\text { os médicos, devem } \\
\text { estar mais } \\
\text { familiarizados com o } \\
\text { direito de acesso à } \\
\text { informação e o direito } \\
\text { de escolher e decidir } \\
\text { dos pacientes. Com } \\
\text { base na divergência } \\
\text { entre as atitudes dos } \\
\text { pacientes e médicos } \\
\text { no estudo, os } \\
\text { pacientes tiveram um } \\
\text { maior nível de } \\
\text { expectativas sobre os } \\
\text { seus direitos em } \\
\text { relação aos médicos. }\end{array}$ \\
\hline
\end{tabular}




\begin{tabular}{|c|c|c|c|c|c|}
\hline & & $\begin{array}{l}\text { público } \\
\text { privado). }\end{array}$ & & & \\
\hline $\begin{array}{l}\text { Observanc } \\
\text { e of } \\
\text { Patient's } \\
\text { Rights: A } \\
\text { Survey on } \\
\text { the Views } \\
\text { of } \\
\text { Patients, } \\
\text { Nurses, } \\
\text { and } \\
\text { Physicians } \\
\text {. }\end{array}$ & $\begin{array}{l}\text { Parsapoor, } \\
\text { A., } \\
\text { Mohammad, } \\
\text { K.; Afzali, H.; } \\
\text { Ala'eddini, F.; } \\
\text { Larijani, B. } \\
\text { J Med Ethics } \\
\text { Hist Med } \\
2012\end{array}$ & $\begin{array}{l}\text { Comparar os } \\
\text { pontos de } \\
\text { vista dos } \\
\text { principais } \\
\text { interveniente } \\
\mathrm{s} \text {, incluindo } \\
\text { pacientes, } \\
\text { médicos e } \\
\text { enfermeiros } \\
\text { em hospitais } \\
\text { que } \\
\text { representam } \\
\text { três modelos } \\
\text { de prestação } \\
\text { de serviços } \\
\text { médicos, } \\
\text { incluindo o } \\
\text { ensino, } \\
\text { privado e } \\
\text { hospitais } \\
\text { públicos, } \\
\text { sobre os } \\
\text { direitos do } \\
\text { paciente, } \\
\text { dentre eles o } \\
\text { direito à } \\
\text { informação. }\end{array}$ & $\begin{array}{l}\text { Estudo } \\
\text { descritivo } \\
\text {-analítico- } \\
\text { transvers } \\
\text { al; } \\
\\
\text { Amostra: } \\
143 \\
\text { pacientes } \\
, \quad 143 \\
\text { enfermeir } \\
\text { os; } \\
\text { Instrume } \\
\text { nto: } \\
\text { questioná } \\
\text { rios } \\
\text { (escala } \\
\text { Likert). }\end{array}$ & $\begin{array}{lr}\text { Os resultados } \\
\text { deste } \quad \text { estudo } \\
\text { mostraram que os } \\
\text { grupos analisados } \\
\text { tinham opiniões } \\
\text { diferentes sobre a } \\
\text { forma como foram } \\
\text { observados } \\
\text { diversos aspectos } \\
\text { dos direitos dos } \\
\text { pacientes. } \\
\text { maior nível de } \\
\text { discordância foi } \\
\text { relacionado ao } \\
\text { direito ro de } \\
\text { escolher e decidir } \\
\text { pelos pacientes, } \\
\text { que não foi } \\
\text { satisfatório no } \\
\text { hospital de } \\
\text { ensino. }\end{array}$ & 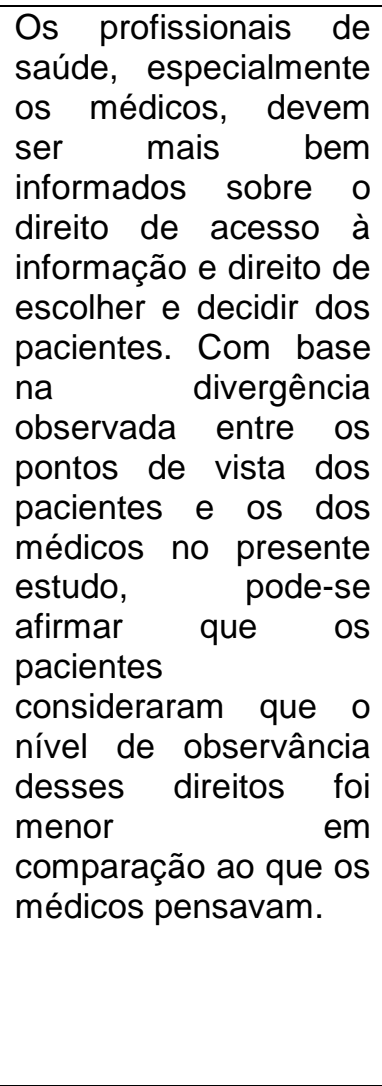 \\
\hline $\begin{array}{l}\text { Unsatisfie } \\
\text { d patient's } \\
\text { rights: A } \\
\text { survey on } \\
\text { the views } \\
\text { of } \\
\text { patients, } \\
\text { nurses } \\
\text { and } \\
\text { physicians } \\
\text {. }\end{array}$ & $\begin{array}{l}\text { Parsapoor, } \\
\text { A., } \\
\text { Mohammad, } \\
\text { K.; Afzali, H.; } \\
\text { Ala'eddini, F.; } \\
\text { Larijani, B. } \\
\text { J Med Ethics } \\
\text { Hist Med } \\
2012\end{array}$ & $\begin{array}{l}\text { Comparar os } \\
\text { pontos de } \\
\text { vista dos } \\
\text { pacientes, } \\
\text { como } \\
\text { destinatários } \\
\text { de serviços } \\
\text { de saúde e } \\
\text { os médicos } \\
\text { e enfermeiros, } \\
\text { como } \\
\text { profissionais } \\
\text { de saúde, } \\
\text { sobre as } \\
\text { demandas } \\
\text { não satisfeitas de } \\
\text { diferentes } \\
\text { aspectos } \\
\text { dos direitos } \\
\text { dos pacientes } \\
\text { pa três } \\
\text { em hospitais } \\
\text { que }\end{array}$ & $\begin{array}{l}\text { Estudo } \\
\text { descritivo } \\
- \\
\text { analítico- } \\
\text { transvers } \\
\text { al. } \\
\text { Amostra: } \\
143 \\
\text { pacientes } \\
\text {, } \quad 143 \\
\text { enfermeir } \\
\text { os; } \\
\text { Instrume } \\
\text { nto: } \\
\text { questioná } \\
\text { rios } \\
\text { (escala } \\
\text { Likert). }\end{array}$ & $\begin{array}{l}\text { Os resultados } \\
\text { mostraram que os } \\
\text { grupos estudados } \\
\text { tinham } \\
\text { significativamente } \\
\text { diferentes pontos } \\
\text { de vista. A maior } \\
\text { divergência } \\
\text { aparece quando } \\
\text { os pacientes } \\
\text { precisam tomar } \\
\text { uma decisão } \\
\text { informada. Neste } \\
\text { caso, a questão } \\
\text { sobre a tomada } \\
\text { de decisão foi } \\
\text { particularmente } \\
\text { insatisfatória no } \\
\text { hospital de } \\
\text { ensino. Indicam } \\
\text { também que os } \\
\text { profissionais de } \\
\text { saúde, } \\
\text { especialmente os } \\
\text { médicos, mostrar } \\
\text { precisam ma }\end{array}$ & $\begin{array}{lr}\text { Houve uma diferença } \\
\text { significativa entre as } \\
\text { opiniões dos pacientes } \\
\text { e profissionais de } \\
\text { saúde sobre a } \\
\text { importância ras } \\
\text { demandas das } \\
\text { satisfeitas } \\
\text { relacionadas não } \\
\text { direitos dos pacientes. } \\
\text { De acordo com os } \\
\text { pacientes, o nível de } \\
\text { demandas insatisfeitas } \\
\text { destes direitos é muito } \\
\text { maior do que o } \\
\text { expresso pelos } \\
\text { médicos. }\end{array}$ \\
\hline
\end{tabular}




\begin{tabular}{|c|c|c|c|c|c|}
\hline & & $\begin{array}{l}\text { representam } \\
\text { três tipos de } \\
\text { configuraçõe } \\
\text { s (ensino, } \\
\text { privadas, e } \\
\text { público). }\end{array}$ & & $\begin{array}{l}\text { mais respeito } \\
\text { pelos direitos dos } \\
\text { pacientes em } \\
\text { termos de acesso } \\
\text { à informação } \\
\text { clínica e tomada } \\
\text { de decisões. }\end{array}$ & \\
\hline $\begin{array}{l}\text { Knowledg } \\
\text { e about } \\
\text { patients' } \\
\text { rights } \\
\text { among } \\
\text { profession } \\
\text { als in } \\
\text { public } \\
\text { health care } \\
\text { in Finland. }\end{array}$ & $\begin{array}{l}\text { Iltanen, S.; } \\
\text { Leino-Kilpi, } \\
\text { H.; Puukka, } \\
\text { P.; Suhonen, } \\
\text { R. } \\
\text { Scand J } \\
\text { Caring Sci } \\
2012\end{array}$ & $\begin{array}{l}\text { Descrever o } \\
\text { nível de } \\
\text { conheciment } \\
\text { o dos } \\
\text { profissionais } \\
\text { de saúde } \\
\text { sobre os } \\
\text { direitos dos } \\
\text { pacientes e } \\
\text { descrever a } \\
\text { fundo as } \\
\text { variáveis } \\
\text { associadas } \\
\text { ao } \\
\text { conheciment } \\
\text { o. Os } \\
\text { direitos são } \\
\text { baseados na } \\
\text { legislação } \\
\text { finlandesa } \\
\text { sobre o } \\
\text { Estatuto e } \\
\text { direitos dos } \\
\text { pacientes. }\end{array}$ & $\begin{array}{l}\text { Estudo } \\
\text { descritivo } \\
\text { Amostra: } \\
191 \\
\text { médicos } \\
\text { e } \\
\text { enfermeir } \\
\text { os); } \\
\text { Instrume } \\
\text { nto: } \\
\text { questioná } \\
\text { rio. }\end{array}$ & 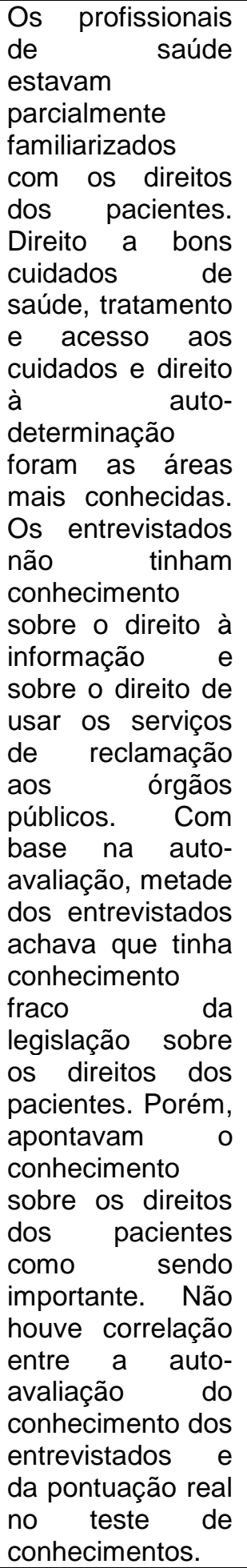 & $\begin{array}{l}\text { Estes resultados } \\
\text { implicam a } \\
\text { necessidade de mais } \\
\text { educação voltada para } \\
\text { profissionais de saúde } \\
\text { e desenvolvimento da } \\
\text { formação profissional } \\
\text { sobre os direitos dos } \\
\text { pacientes. }\end{array}$ \\
\hline
\end{tabular}




\begin{tabular}{|c|c|c|c|c|c|}
\hline $\begin{array}{l}\text { Informed } \\
\text { consent in } \\
\text { hospital } \\
\text { practice: } \\
\text { health } \\
\text { profession } \\
\text { als' } \\
\text { perspectiv } \\
\text { es and } \\
\text { legal } \\
\text { reflections }\end{array}$ & $\begin{array}{l}\text { Heywood, R.; } \\
\text { Macaskill, A.; } \\
\text { Williams, K. } \\
\text { Med Law Rev } \\
2010\end{array}$ & $\begin{array}{l}\text { Explorar em } \\
\text { profundidade } \\
0 \\
\text { conheciment } \\
0 \quad \text { de } \\
\text { médicos e } \\
\text { enfermeiros } \\
\text { sobre o } \\
\text { consentimen } \\
\text { to informado } \\
\text { na atenção } \\
\text { secundária. }\end{array}$ & $\begin{array}{l}\text { Estudo } \\
\text { qualitativ } \\
\text { o- } \\
\text { fenomen } \\
\text { ológico- } \\
\text { hermenê } \\
\text { utico; } \\
\text { Amostra: } \\
14 \\
\text { médicos } \\
\text { e } 6 \\
\text { enfermeir } \\
\text { os } \\
\text { voluntário } \\
\text { s; } \\
\text { Entrevist } \\
\text { as semi- } \\
\text { estrutura } \\
\text { das. }\end{array}$ & 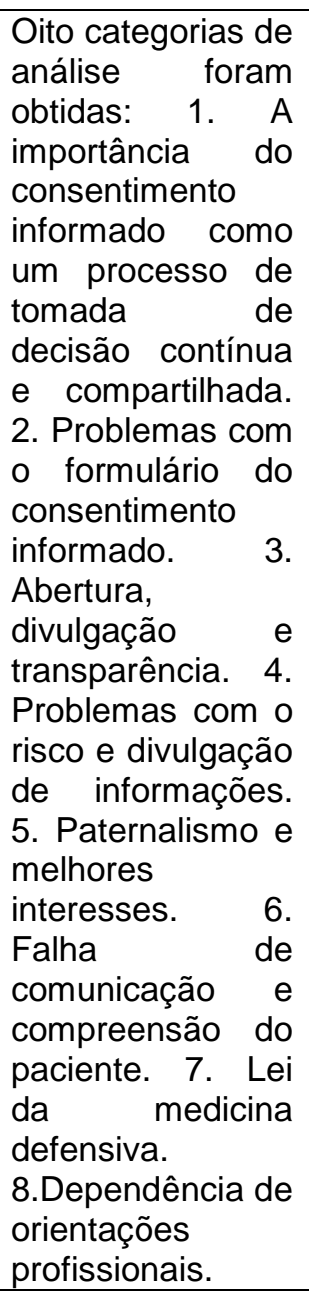 & 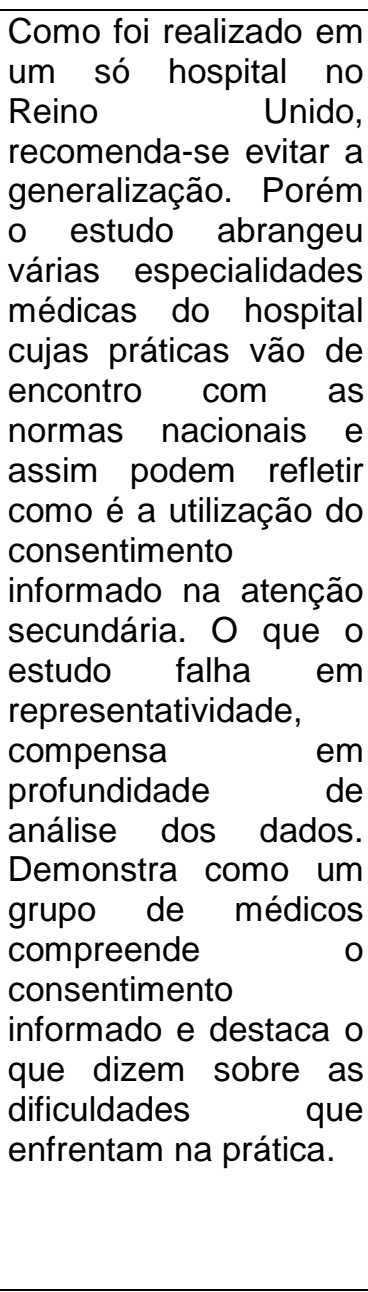 \\
\hline $\begin{array}{l}\text { The effect } \\
\text { of giving } \\
\text { detailed } \\
\text { informatio } \\
n \text { about } \\
\text { intravenou } \\
\text { s } \\
\text { radiophar } \\
\text { maceutical } \\
\text { administra } \\
\text { tion on the } \\
\text { anxiety } \\
\text { level of } \\
\text { patients } \\
\text { who } \\
\text { request } \\
\text { more } \\
\text { informatio } \\
n \text {. }\end{array}$ & $\begin{array}{lr}\text { Kaya, } & \text { E.; } \\
\text { Ciftci, } & \text { I., } \\
\text { Demirel, } & \text { R.; } \\
\text { Cigerci, } & \text { Y.; } \\
\text { Gecici, O. } & \\
\text { Ann } \quad \text { Nucl } \\
\text { Med } \\
2010\end{array}$ & $\begin{array}{l}\text { Descrever o } \\
\text { efeito de } \\
\text { fornecer } \\
\text { informações } \\
\text { sobre a } \\
\text { administraçã } \\
\text { o } \\
\text { intravenosa } \\
\text { do } \\
\text { radiofármaco } \\
\text { no nível de } \\
\text { ansiedade } \\
\text { dos } \\
\text { pacientes } \\
\text { que solicitam } \\
\text { mais } \\
\text { informações. }\end{array}$ & $\begin{array}{l}\text { Estudo } \\
\text { descritivo } \\
; \\
\text { Amostra: } \\
620 \\
\text { pacientes } \\
\text { (247 } \\
\text { homens, } \\
373 \\
\text { mulheres } \\
\text { ) encaminh } \\
\text { ados } \\
\text { para } \\
\text { perfusão } \\
\text { miocárdic } \\
\text { a, osso, } \\
\text { renal } \\
\text { dinâmica, } \\
\text { e os } \\
\text { exames } \\
\text { de } \\
\text { cintilograf } \\
\text { ia da } \\
\text { tireóide; }\end{array}$ & $\begin{array}{l}\text { Não houve } \\
\text { diferença } \\
\text { estatística entre } \\
\text { os grupos } 1 \text { e } 2 \\
\text { em STAI-S ou } \\
\text { pontuações STAI- } \\
\text { T após a simples } \\
\text { informação ter } \\
\text { sido oferecida (p } \\
=0,741 \text { e p = } \\
0,945, \\
\text { respectivamente). } \\
\text { O valor médio de } \\
\text { pontuação no } \\
\text { STAI-S aumentou } \\
\text { após a prestação } \\
\text { de informação } \\
\text { detalhada e } \\
\text { houve } \\
\text { diferença uma } \\
\text { estatisticamente } \\
\text { significativa entre } \\
\text { depois de } \\
\text { informações } \\
\text { simples STAI-S e }\end{array}$ & 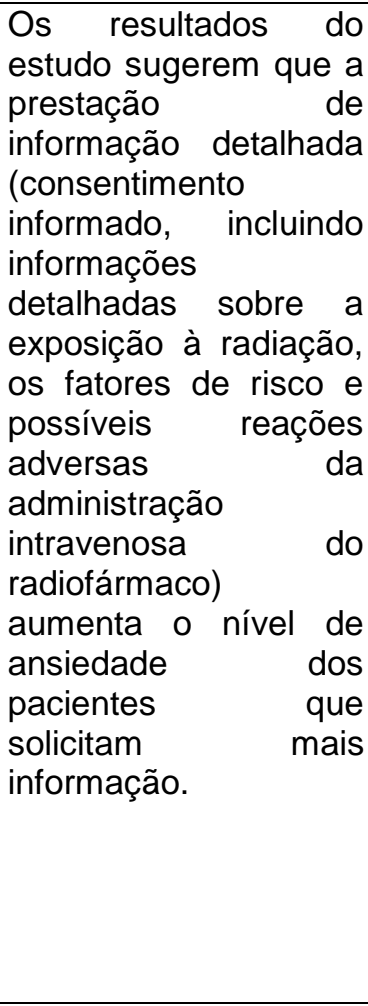 \\
\hline
\end{tabular}




\begin{tabular}{|c|c|c|c|c|c|}
\hline & & & $\begin{array}{l}\text { Instrume } \\
\text { ntos: } \\
\text { State } \\
\text { Trait- } \\
\text { Anxiety } \\
\text { Inventory } \\
\text { (STAI-S e } \\
\text { STAI-T) }\end{array}$ & 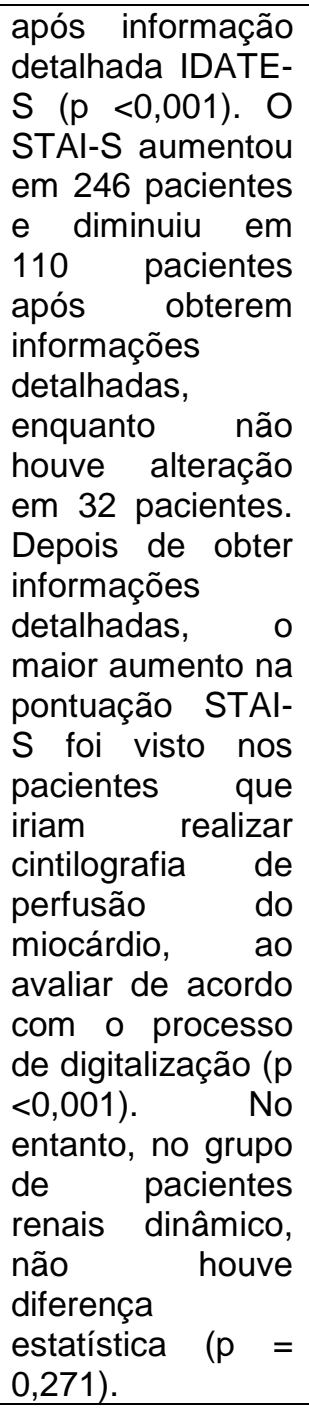 & \\
\hline \begin{tabular}{l}
\multicolumn{2}{l}{ Derechos } \\
de los \\
pacientes. \\
Algo más \\
que uma \\
cuéstion \\
de actitud
\end{tabular} & $\begin{array}{l}\text { Mira, J. J.; } \\
\text { Lorenzo, S.; } \\
\text { Vitaller, J.; } \\
\text { Guilabert, M. } \\
\text { Gac Sanit } \\
2009\end{array}$ & $\begin{array}{l}\text { Analisar o } \\
\text { conheciment } \\
\text { o de } \\
\text { médicos } \\
\text { hospitalares } \\
\text { e da atenção } \\
\text { primária } \\
\text { sobre os } \\
\text { direitos dos } \\
\text { pacientes } \\
\text { recentement } \\
\text { e } \\
\text { modificados } \\
\text { pela Lei } \\
\text { espanhola } \\
41 / 2002 \text { (Lei } \\
\text { da A Autonomia } \\
\text { do } \\
\text { Paciente). }\end{array}$ & $\begin{array}{l}\text { Estudo } \\
\text { descritivo } \\
\text { Pesquisa } \\
\text { voluntária } \\
\text { com } \\
\text { médicos } \\
\text { hospitalar } \\
\text { es e de } \\
\text { cuidados } \\
\text { primários } \\
\text { em que } \\
\text { foram } \\
\text { apresent } \\
\text { adas três } \\
\text { situações } \\
\text { problemá } \\
\text { ticas } \\
\text { retirados } \\
\text { de } \\
\text { decisões } \\
\text { judiciais e }\end{array}$ & 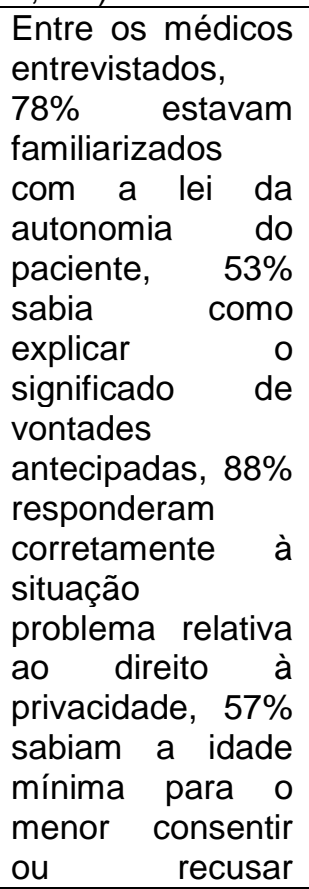 & $\begin{array}{l}\text { Pelo menos um em } \\
\text { cada } 10 \text { médicos } \\
\text { poderiam } \\
\text { legalmente } \\
\text { responsabilizados por } \\
\text { falta de conhecimento } \\
\text { da Lei da Autonomia } \\
\text { do Paciente. Os } \\
\text { pacientes com idade } \\
\text { entre } 16 \text { e } 18 \text { anos } \\
\text { têm maior dificuldade } \\
\text { de terem seus direitos } \\
\text { respeitados por falta } \\
\text { de conhecimento da } \\
\text { lei. Informações } \\
\text { prévias sobre a Lei da } \\
\text { Autonomia r do } \\
\text { Paciente contribuem } \\
\text { para a maior } \\
\text { cumprimento dos }\end{array}$ \\
\hline
\end{tabular}




\begin{tabular}{|c|c|c|c|c|c|}
\hline & & & $\begin{array}{l}\text { da lei da } \\
\text { autonomi } \\
\text { a do } \\
\text { paciente. }\end{array}$ & 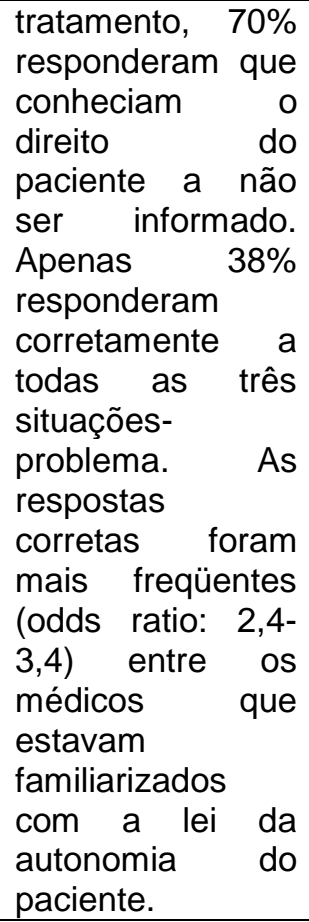 & direitos. \\
\hline $\begin{array}{l}\text { Is the right } \\
\text { to } \\
\text { informatio } \\
n \text { fulfilled } \\
\text { in an } \\
\text { emergency } \\
\text { departmen } \\
t ? \\
\text { Patients' } \\
\text { perception } \\
s \text { of the } \\
\text { care } \\
\text { provided. }\end{array}$ & $\begin{array}{l}\text { Pérez- } \\
\text { Cárceles, M. } \\
\text { D.; Gironda, } \\
\text { J. L.; Osuna, } \\
\text { E.; Falcon, } \\
\text { M.; Luna, A. } \\
\text { Journal of } \\
\text { Evaluation in } \\
\text { Clinical } \\
\text { Practice } \\
2010\end{array}$ & $\begin{array}{l}\text { Avaliar a } \\
\text { medida em } \\
\text { que o direito } \\
\text { à informação } \\
\text { é cumprido } \\
\text { em uma } \\
\text { Unidade de } \\
\text { Emergência; } \\
\text { verificar o } \\
\text { grau de } \\
\text { satisfação } \\
\text { do paciente } \\
\text { com a } \\
\text { atenção } \\
\text { recebida e } \\
\text { avaliar a } \\
\text { relação entre } \\
\text { a satisfação } \\
\text { e as } \\
\text { informações } \\
\text { recebidas, o } \\
\text { tempo de } \\
\text { espera e a } \\
\text { gravidade da } \\
\text { emergência. }\end{array}$ & $\begin{array}{l}\text { Estudo } \\
\text { descritivo } \\
- \\
\text { transvers } \\
\text { al; } \\
\text { Amostra: } \\
300 \\
\text { pacientes } \\
\text { que } \\
\text { consultar } \\
\text { am uma } \\
\text { Unidade } \\
\text { de } \\
\text { Emergên } \\
\text { cia } \\
\text { durante } \\
\text { um } \\
\text { período } \\
\text { de } \\
\text { meses. } \\
\end{array}$ & 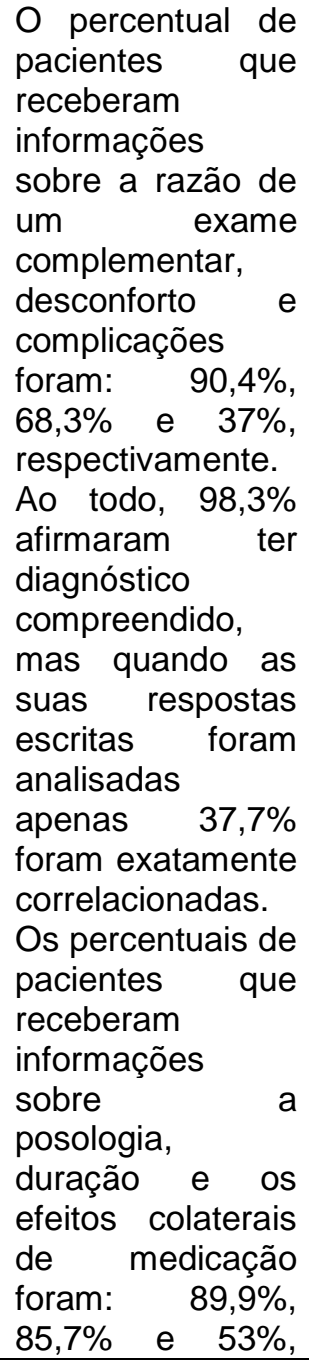 & $\begin{array}{l}\text { Fornecer a informação } \\
\text { em todas as fases do } \\
\text { processo de cuidado, } \\
\text { dando a oportunidade } \\
\text { para o paciente fazer } \\
\text { perguntas, } \\
\text { dúvidas sanar } \\
\text { instruções de dar } \\
\text { legíveis e de fácil } \\
\text { compreensão } \\
\text { fatores que contribuem } \\
\text { para o aumento da } \\
\text { satisfação do paciente } \\
\text { em uma Unidade de } \\
\text { Emergência. }\end{array}$ \\
\hline
\end{tabular}




\begin{tabular}{|c|c|c|c|c|c|}
\hline & & & $\begin{array}{l}\text { ográficas, } \\
\text { variáveis } \\
\text { relaciona } \\
\text { das com } \\
\text { o } \\
\text { tratament } \\
\text { o } \\
\text { recebido } \\
\text { e } \\
\text { satisfaçã } \\
\text { o geral } \\
\text { foram } \\
\text { obtidos. } \\
\text { Registros } \\
\text { médicos } \\
\text { também } \\
\text { foram } \\
\text { analisado } \\
\text { s. }\end{array}$ & 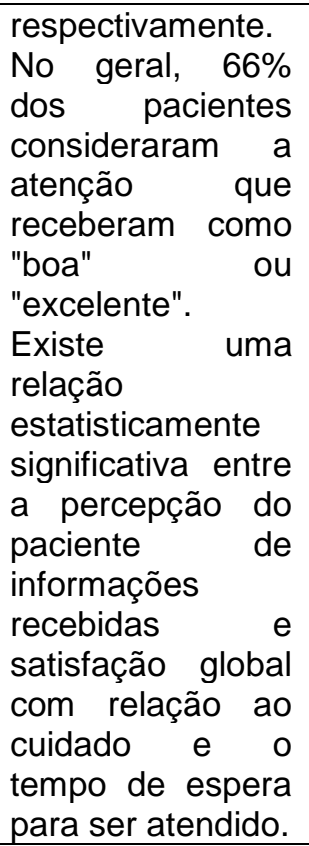 & \\
\hline $\begin{array}{l}\text { Why do } \\
\text { people } \\
\text { want a } \\
\text { paper } \\
\text { copy of } \\
\text { their } \\
\text { electronic } \\
\text { patient } \\
\text { record? }\end{array}$ & $\begin{array}{l}\text { Wibe,T.; } \\
\text { Ekstedt, M.; } \\
\text { Helleso, R.; } \\
\text { Slaughter, L. } \\
\text { Stud Health } \\
\text { Technol } \\
\text { Inform } \\
2010\end{array}$ & $\begin{array}{l}\text { Identificar as } \\
\text { razões pelas } \\
\text { quais os } \\
\text { pacientes } \\
\text { solicitam } \\
\text { cópias de } \\
\text { seus } \\
\text { registros. }\end{array}$ & $\begin{array}{l}\text { Estudo } \\
\text { qualitativ } \\
\text { o- } \\
\text { explorató } \\
\text { rio; } \\
\text { Amostra: } \\
17 \\
\text { pacientes } \\
\text { voluntário } \\
\text { s que } \\
\text { tivessem } \\
\text { solicitado } \\
\text { copias de } \\
\text { seus } \\
\text { registros } \\
\text { médicos. }\end{array}$ & 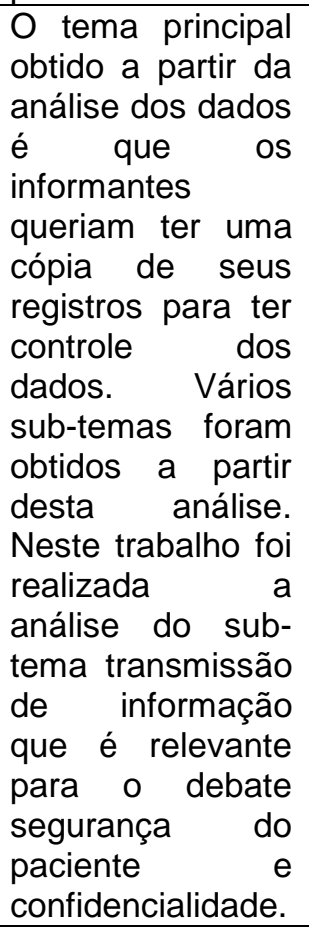 & $\begin{array}{l}\text { Há necessidade de } \\
\text { organização do } \\
\text { conteúdo dos registros } \\
\text { eletrônicos, bem como } \\
\text { flexibilidade de acesso } \\
\text { por parte dos usuários } \\
\text { do serviço. Podem ser } \\
\text { realizadas melhorias } \\
\text { no sistema de } \\
\text { transmissão de } \\
\text { informações entre } \\
\text { instituições de saúde, } \\
\text { fazendo com que os } \\
\text { usuários se sintam } \\
\text { mais seguros em } \\
\text { relação aos registros, } \\
\text { evitando que solicitem } \\
\text { cópia de seus } \\
\text { prontuários. }\end{array}$ \\
\hline $\begin{array}{l}\text { The views } \\
\text { of cancer } \\
\text { patients } \\
\text { on patient } \\
\text { rights in } \\
\text { the } \\
\text { context of } \\
\text { informatio } \\
n \text { and } \\
\text { autonomy. }\end{array}$ & $\begin{array}{l}\text { J Med Ethics } \\
\text { Erer, S.; Atici, } \\
\text { E.; Erdemir, } \\
\text { A. D. } \\
2008\end{array}$ & $\begin{array}{l}\text { Avaliar os } \\
\text { pontos de } \\
\text { vista dos } \\
\text { pacientes } \\
\text { com câncer } \\
\text { sobre os } \\
\text { seus } \\
\text { direitos, no } \\
\text { contexto do } \\
\text { direito à } \\
\text { informação e } \\
\text { autonomia } \\
\end{array}$ & $\begin{array}{l}\text { Estudo } \\
\text { descritivo } \\
\text { Amostra: } \\
104 \\
\text { pacientes } \\
\text { com } \\
\text { câncer da } \\
\text { unidade } \\
\text { de } \\
\text { oncologia } \\
\text { médica } \\
\end{array}$ & 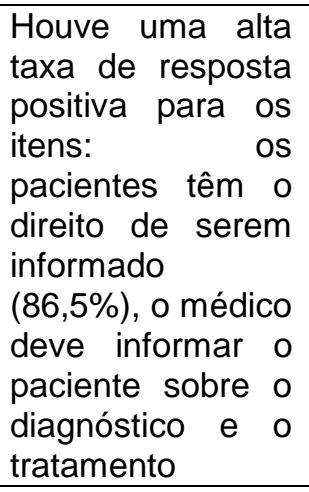 & $\begin{array}{l}\text { Há grandes esforços } \\
\text { na Turquia no sentido } \\
\text { de tornar os direitos } \\
\text { dos pacientes como } \\
\text { um componente de } \\
\text { apoio significativo aos } \\
\text { serviços de saúde. } \\
\text { Visando que os } \\
\text { direitos do paciente se } \\
\text { tornem uma parte } \\
\text { natural da prática } \\
\text { médica, é necessário }\end{array}$ \\
\hline
\end{tabular}




\begin{tabular}{|c|c|c|c|c|c|}
\hline & & $\begin{array}{lr}\text { de acordo } \\
\text { com } & \text { os } \\
\text { artigos } & \\
\text { relacionados } \\
\text { com r a } \\
\text { questão na } \\
\text { Norma de } \\
\text { Direitos do } \\
\text { Paciente. }\end{array}$ & $\begin{array}{l}\text { de um } \\
\text { hospital } \\
\text { de } \\
\text { pesquisa } \\
\text { e prática } \\
\text { na } \\
\text { Turquia, } \\
\text { Instrume } \\
\text { nto: } \\
\text { entrevista } \\
\text { s face-a- } \\
\text { face, com } \\
\text { utilização } \\
\text { de } \\
\text { questioná } \\
\text { rio. }\end{array}$ & 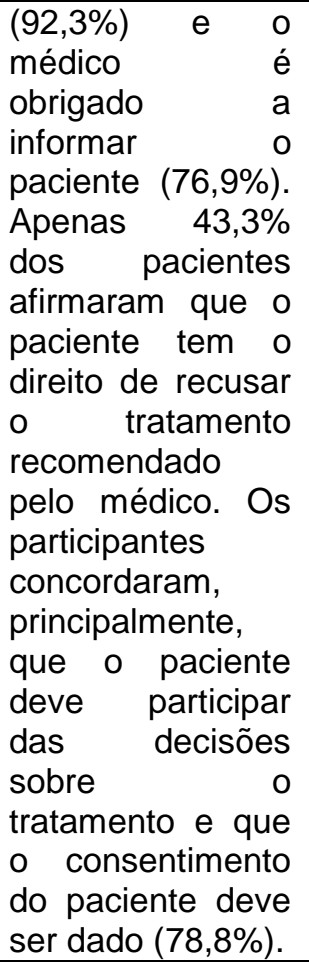 & $\begin{array}{l}\text { dar prioridade à } \\
\text { educação } \\
\text { pacientes e médicos } \\
\text { sobre os direitos dos } \\
\text { pacientes e dar ênfase } \\
\text { a uma abordagem } \\
\text { ética na relação } \\
\text { médico-paciente. }\end{array}$ \\
\hline $\begin{array}{l}\text { Minors } \\
\text { and } \\
\text { informed } \\
\text { consent: a } \\
\text { comparati } \\
\text { ve } \\
\text { approach }\end{array}$ & $\begin{array}{l}\text { Stultiens, L.; } \\
\text { Goffin, T.; } \\
\text { Borry, P.; } \\
\text { Dierickx; Nys, } \\
\text { H. } \\
\text { Eur J Health } \\
\text { Law } \\
2007\end{array}$ & $\begin{array}{l}\text { Fazer uma } \\
\text { comparação } \\
\text { global da } \\
\text { posição legal } \\
\text { do paciente } \\
\text { menor de } \\
\text { idade em } \\
\text { relação ao } \\
\text { direito de ser } \\
\text { informado e } \\
\text { ter } \\
\text { capacidade } \\
\text { de decisão } \\
\text { sobre suas } \\
\text { intervenções } \\
\text { de saúde na } \\
\text { União } \\
\text { Européia. }\end{array}$ & $\begin{array}{l}\text { Estudo } \\
\text { comparati } \\
\text { vo de leis } \\
\text { dos } \\
\text { países da } \\
\text { União } \\
\text { Européia } \\
\text { sobre o } \\
\text { consenti } \\
\text { mento } \\
\text { informad } \\
\text { o da } \\
\text { criança. } \\
\text { Países } \\
\text { analisado } \\
\text { s: Chipre, } \\
\text { Republic } \\
\text { a Checa, } \\
\text { Dinamarc } \\
\text { a, } \\
\text { Estônia, } \\
\text { Grécia, } \\
\text { Hungria, } \\
\text { Lituânia, } \\
\text { Portugal, } \\
\text { Eslováqui } \\
\text { a, } \\
\text { Eslovênia } \\
\text {, Hungria } \\
\text { e Espanha. } \\
\text { Espana }\end{array}$ & 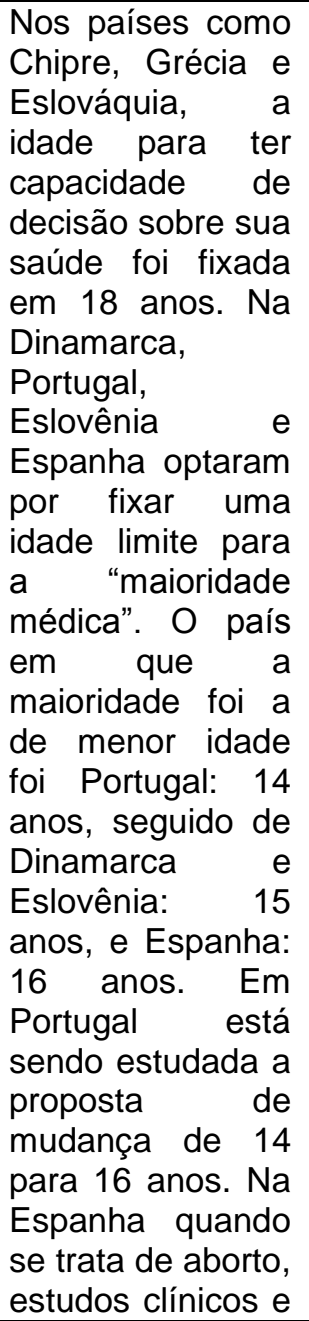 & $\begin{array}{l}\text { A pesquisa mostra que } \\
\text { a posição legal do } \\
\text { menor em relação à } \\
\text { capacidade de decisão } \\
\text { sobre o cuidado em } \\
\text { saúde nos Estados } \\
\text { membros pode ser } \\
\text { dividida em } 4 \\
\text { categorias: } \\
\text { Capacidade } \\
\text { tomada de decisão } \\
\text { legal apenas a partir } \\
\text { da maioridade. } \\
\text { Capacidade de } \\
\text { tomada de decisão } \\
\text { legal abaixo da idade } \\
\text { da maioridade legal } \\
\text { fixada nama } \\
\text { determinada } \\
\text { (idade da maioridade } \\
\text { médica). } \\
\text { Capacidade } \\
\text { tomada de decisão } \\
\text { legal avaliada caso a } \\
\text { caso de acordo com a } \\
\text { idade e maturidade. } \\
\text { Capacidade } \\
\text { tomada de decisão } \\
\text { legal abaixo da idade } \\
\text { da maioridade legal } \\
\text { baseada em idade } \\
\text { limite fixada e também } \\
\text { na avaliação caso a }\end{array}$ \\
\hline
\end{tabular}




\begin{tabular}{|c|c|c|c|c|c|}
\hline & & & & 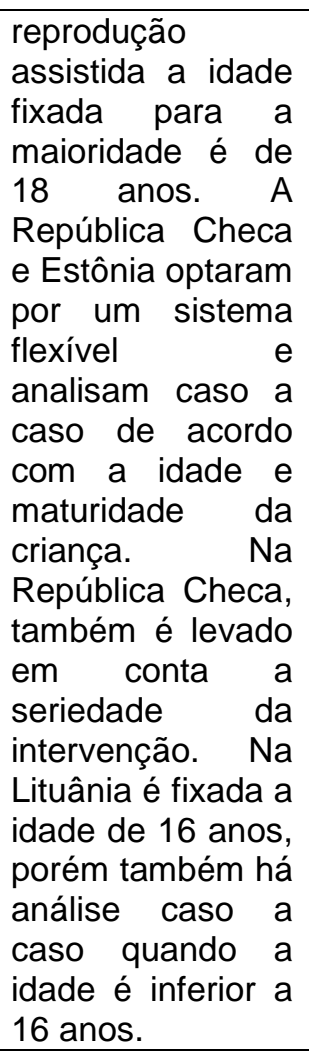 & $\begin{array}{l}\text { caso de acordo com } \\
\text { idade e maturidade. }\end{array}$ \\
\hline $\begin{array}{l}\text { The } \\
\text { patient's } \\
\text { right to } \\
\text { informatio } \\
\text { n: } \\
\text { influence } \\
\text { of socio- } \\
\text { profession } \\
\text { al factors } \\
\text { in primary } \\
\text { care. }\end{array}$ & $\begin{array}{l}\text { Pérez- } \\
\text { Carceles, } \\
\text { M.D.; } \\
\text { Pereñiguez- } \\
\text { Barranco, } \\
\text { J.E.; Osuna- } \\
\text { Carrillo de } \\
\text { Albornoz, E.; } \\
\text { Luna- } \\
\text { Maldonado, } \\
\text { A. } \\
\text { Aten Primaria } \\
2006\end{array}$ & $\begin{array}{l}\text { Descrever } \\
\text { as } \\
\text { informações } \\
\text { fornecidas } \\
\text { pelos } \\
\text { médicos da } \\
\text { atenção } \\
\text { primária } \\
\text { para seus } \\
\text { pacientes } \\
\text { em } \\
\text { diferentes do } \\
\text { fases de } \\
\text { processo de } \\
\text { prestação de } \\
\text { cuidados e } \\
\text { analisar } \\
\text { quaisquer } \\
\text { relações } \\
\text { com fatores } \\
\text { sócio- } \\
\text { profissionais. }\end{array}$ & $\begin{array}{l}\text { Estudo } \\
\text { descritiv } \\
\text { o- } \\
\text { transvers } \\
\text { al; } \\
\text { Amostra: } \\
227 \\
\text { médicos } \\
\text { de } \\
\text { família; } \\
\text { Instrume } \\
\text { nto: } \\
\text { question } \\
\text { ário } \\
\text { (escala } \\
\text { Likert). }\end{array}$ & 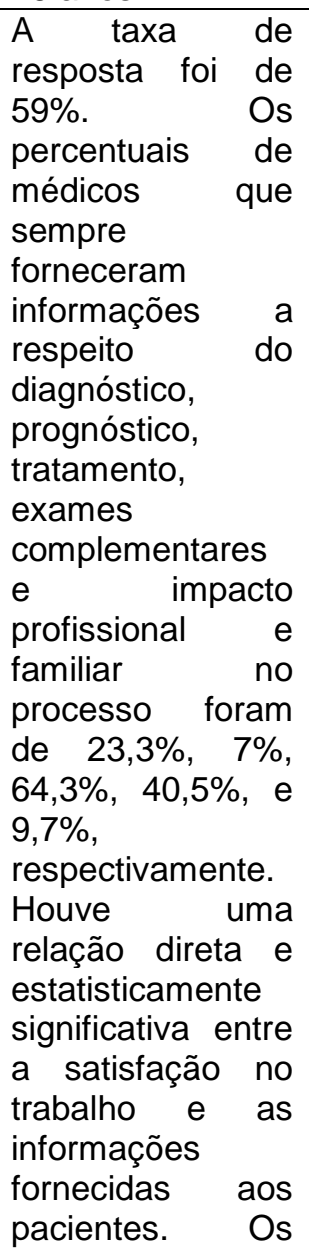 & $\begin{array}{l}\text { O grau de } \\
\text { cumprimento do direito } \\
\text { do paciente à } \\
\text { informação é baixo. } \\
\text { Os médicos devem } \\
\text { perceber a importância } \\
\text { prática da informação } \\
\text { clínica em seu } \\
\text { trabalho. Há um } \\
\text { sentimento geral de } \\
\text { descontentamento } \\
\text { entre os médicos de } \\
\text { família, que têm um } \\
\text { impacto negativo na } \\
\text { sua atividade } \\
\text { profissional. A carga } \\
\text { de trabalho mais leve } \\
\text { iria rar melhorar } \\
\text { significativamente a } \\
\text { medida em que os } \\
\text { médicos fornecessem } \\
\text { aos pacientes } \\
\text { informações. Nesse } \\
\text { contexto, mecanismos } \\
\text { devem ser } \\
\text { estabelecidos para } \\
\text { melhorar as condições } \\
\text { de trabalho e evitar o } \\
\text { não cumprimento do }\end{array}$ \\
\hline
\end{tabular}




\begin{tabular}{|c|c|c|c|c|c|}
\hline & & & & $\begin{array}{lr}\text { médicos sentem } \\
\text { mais satisfação } \\
\text { fornecendo o } \\
\text { máximo } \\
\text { informações de } \\
\text { sobre as } \\
\text { diferentes fases } \\
\text { do processo de } \\
\text { cuidar. Por outro } \\
\text { lado, houve uma } \\
\text { relação inversa e } \\
\text { estatisticamente } \\
\text { significativa entre } \\
\text { o número de } \\
\text { pacientes } \\
\text { agendados dos } \\
\text { médicos e as } \\
\text { informações } \\
\text { fornecidas. }\end{array}$ & $\begin{array}{l}\text { direito do paciente à } \\
\text { informação. }\end{array}$ \\
\hline $\begin{array}{l}\text { Obeying } \\
\text { patient's } \\
\text { rights on } \\
\text { the basis } \\
\text { of } \\
\text { maternity } \\
\text { ward. }\end{array}$ & $\begin{array}{l}\text { Leszczynska, } \\
\text { K.; Dymczyk, } \\
\text { K.; } \\
\text { Krajewska, K. } \\
\text { Annales } \\
\text { Accademiae } \\
\text { Medicae } \\
\text { Bialostocensi } \\
\text { s } \\
2005\end{array}$ & $\begin{array}{lr}\text { Avaliar o } \\
\text { grau de } \\
\text { conheciment } \\
\text { o sobre } \\
\text { direitos e } \\
\text { chances de } \\
\text { paciente } \\
\text { para exercer } \\
\text { estes } \\
\text { direitos na } \\
\text { realidade } \\
\text { hospitalar de } \\
\text { um hospital } \\
\text { na Polônia. }\end{array}$ & $\begin{array}{l}\text { Estudo } \\
\text { descritivo } \\
\text { Amostra: } \\
227 \\
\text { mulheres } \\
\text { hospitaliz } \\
\text { adas em } \\
\text { uma } \\
\text { maternid } \\
\text { ade e } \\
\text { salas de } \\
\text { parto. } \\
\text { Utilização } \\
\text { de } \\
\text { questioná } \\
\text { rio } \\
\text { especial } \\
\text { mente } \\
\text { preparad } \\
\text { o para } \\
\text { avaliar os } \\
\text { direitos } \\
\text { da } \\
\text { paciente } \\
\text { nos } \\
\text { seguintes } \\
\text { aspectos: } \\
\text { o direito a } \\
\text { tomada } \\
\text { de } \\
\text { decisão, } \\
\text { o direito à } \\
\text { informaçã } \\
\text { o, } \\
\text { incluindo } \\
\text { o direito } \\
\text { de }\end{array}$ & $\begin{array}{l}\text { Os resultados } \\
\text { indicam que o } \\
\text { conhecimento } \\
\text { sobre os direitos } \\
\text { da paciente nesta } \\
\text { unidade de saúde } \\
\text { é insuficiente. } \\
\text { Mais de } 60 \% \\
\text { nunca ouviu falar } \\
\text { sobre } \\
\text { regulamentos de } \\
\text { proteção. Dos } \\
40 \% \text { restantes, } \\
66.7 \text { tiveram } \\
\text { informação com a } \\
\text { equipe de saúde } \\
\text { (53,4\% com } \\
\text { médicos; 13,7\% } \\
\text { com enfermeiros). }\end{array}$ & 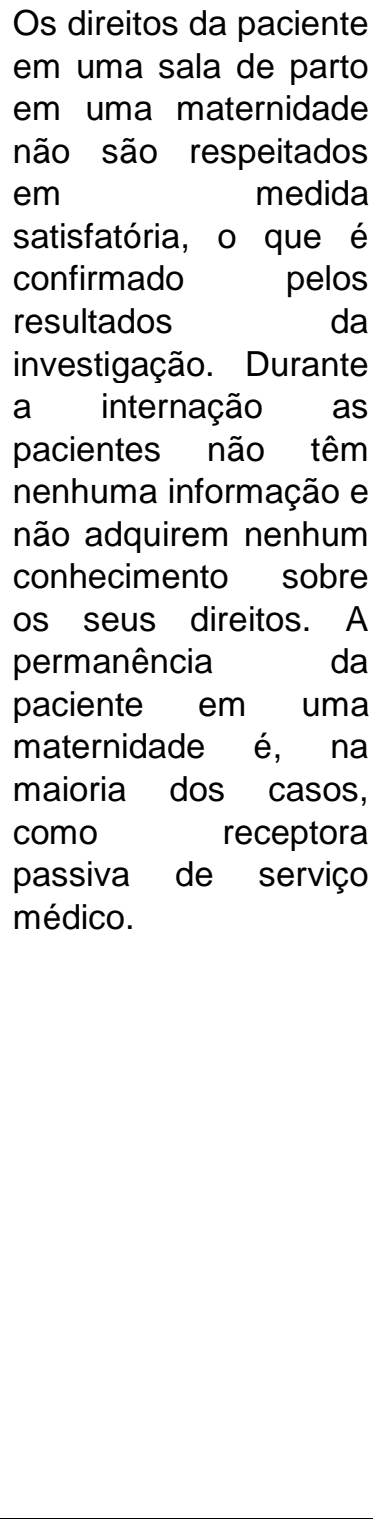 \\
\hline
\end{tabular}




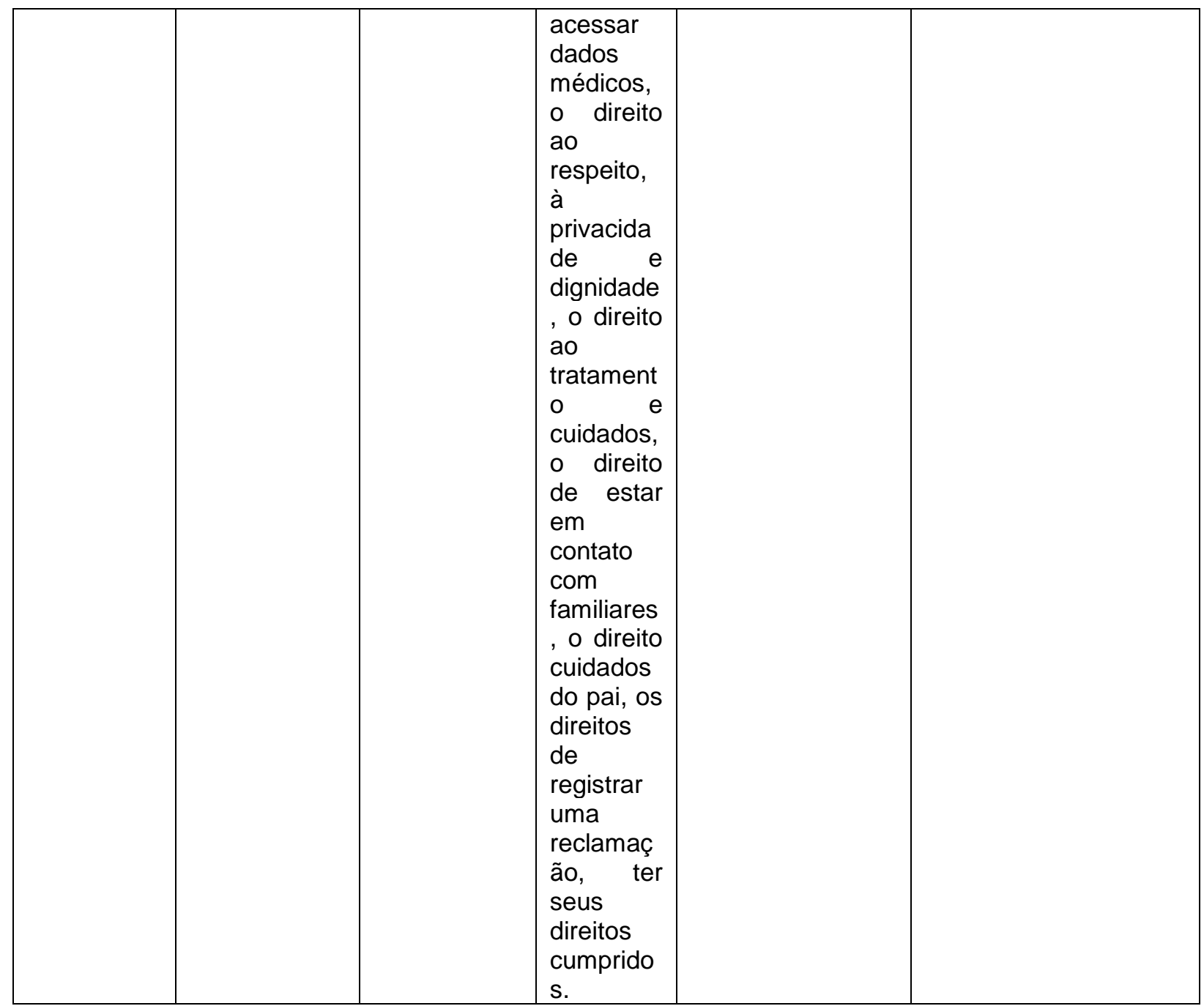

\section{Discussão}

O conceito de saúde mais difundido atualmente é o proposto pela Organização Mundial da Saúde (OMS) no preâmbulo de sua Constituição, de 1946: "saúde é o estado de completo bem-estar físico, mental e social, e não somente a ausência de doenças ou enfermidades (13). Esta definição reconhece o ser humano como ser integral e a saúde como qualidade de vida. Atualmente, enfatiza-se uma visão ampliada de saúde em que a atenção à saúde incorpore ao ato terapêutico a valorização do outro, respeitando sua visão de mundo, seu contexto social e sua dignidade, dando destaque para a qualidade de vida e enfatizando as estratégias de promoção, prevenção, cura e reabilitação (14).

O reconhecimento da saúde como um direito universal e integral esbarra no estágio de desenvolvimento insuficiente do Estado para sua garantia (3). Por estar entre os direitos fundamentais sociais, ou prestacionais, o direito à saúde constitui um dos elementos que 
marcam o constitucionalismo liberal para o constitucionalismo social, para a existência no texto constitucional de direitos à prestação, direitos que impõem um dever ao Estado (15).

Nesse cenário, os direitos sociais não exigem do Estado uma postura de abstenção, mas uma postura positiva. Assim, esses direitos se tornam essenciais tanto por sua universalidade, quanto por sua eficácia, e estão ligados intimamente a direitos prestacionais sociais do Estado perante o indivíduo, bem como assistência social, educação, saúde, cultura e trabalho (16).

O direito à informação em saúde é um dos princípios das Cartas de Direito do Usuário e implica em que todo usuário do serviço de saúde tem direito a receber informações relevantes sobre sua saúde, tratamentos médicos e serviços de saúde (17).

As categorias temáticas desta revisão integrativa foram agrupadas de acordo com o conhecimento dos usuários sobre seu direito à informação e conhecimento dos profissionais sobre o direito à informação do usuário.

\section{Conhecimento de usuários sobre seu direito à informação}

Estudos desta revisão que discutiram sobre o conhecimento de usuários sobre seu direito à informação abordaram esta questão juntamente com outros direitos do usuário, sempre utilizando as Cartas de Direito do Usuário do país de origem como referência (18), (19), (20), (21). Outras abordagens foram encontradas ainda nos estudos selecionados: o efeito de fornecer informações sobre administração de um radiofármaco (22); 0 cumprimento do direito à informação relacionado à satisfação do usuário numa unidade de emergência (23); razões pelas quais os usuários solicitam cópias de seus prontuários (24) e comparação entre diversos países da União Européia sobre o direito do menor de ser informado sobre seu tratamento (25).

Em estudo desta revisão (18), 85\% dos participantes relataram que é importante o direito à informação do usuário sobre seu estado de saúde. Todos os direitos relacionados ao usuário foram considerados importantes neste estudo, porém foram evidenciados como mais importantes o direito à dignidade no final da vida, ou seja, o direito de morrer com dignidade, direito à saúde acessível, direito à informação em saúde, eutanásia e qualidade do cuidado em saúde e cuidados paliativos. Nesta revisão o foco recai sobre o direito à saúde acessível e o direito à informação em saúde. 
Nesse sentido, observa-se que os países estão buscando adequar suas legislações internas visando assegurar o direito à informação em saúde dos usuários dos serviços de saúde. Dessa forma, as evidências encontradas nesta revisão integrativa corroboram com os termos da legislação brasileira, especialmente da Lei 8080/1990 (26) e da Carta de Direitos dos Usuários em que são explicitados que todo usuário tem direito a informações sobre seu estado de saúde, de maneira clara, objetiva, respeitosa e compreensível (27) e também direito à informação às pessoas assistidas, sobre sua saúde e direito a saúde universal (26).

No entanto, houve um estudo (28) que discutiu sobre o acesso dos usuários aos serviços de saúde e seus direitos durante a internação, bem como acesso à informação sobre sua doença, o seu prognóstico e complicações comuns em linguagem compreensível, identificou pequena necessidade de acesso dos usuários aos seus registros médicos.

Diante do que prevê o direito à informação em saúde na Carta de Direitos dos Usuários (27) sobre informações claras, objetivas, respeitosa e compreensível, enfatiza-se ao conceito do "padrão-subjetivo", ou seja, a informação deve ser direcionada a cada usuário do serviço (29). As informações devem ser prestadas de acordo com a personalidade, o grau de conhecimento e as condições clínicas e psíquicas do usuário, deixando claros dados do diagnóstico ao prognóstico, dos tratamentos a efetuar, dos riscos e benefícios e alternativas, se existirem. Quanto à forma de fornecimento das informações, dizem ainda que pode ser oral ou por escrito, desde que haja certeza da compreensão dos dados (30).

Outro estudo (31) discutiu a questão do "padrão-subjetivo", abordagem informativa apropriada a cada indivíduo, adaptando valores e expectativas psicológicas e sociais de cada pessoa, sem se ater a fórmulas padronizadas. O estudo mostrou que, em uma unidade de emergência, o contato médico-usuário é mais rápido, assim algumas dúvidas persistem, pois o médico tem uma maior quantidade de usuários a serem atendidos e não tem tempo para resolver todas as questões do usuário. Nas unidades de emergência, a comunicação é reconhecida como um fator chave da satisfação do usuário, e problemas com a comunicação são evidenciados como principal causa de reclamação do usuário. Neste caso, há uma relação entre a informação recebida e a satisfação do usuário. 
Os usuários devem ser considerados únicos, não padronizáveis e o consentimento com a adequada informação deve basear-se não só na escolha de uma melhor alternativa científica, mas na melhor alternativa para aquela pessoa (32), (33), (29).

Houve um outro estudo (28) que abordou o direito à informação do usuário, no que se refere à informação clínica e tomada de decisão sobre sua saúde, resultando em alta taxa de insatisfação do usuário, requerendo maior atenção na comunicação profissionalusuário. De acordo com os usuários, eles pedem a informação diretamente ao médico, e acreditam que este profissional é o responsável por esta informação. Este é um direito explícito na Carta de Direitos dos Usuários tanto do Irã, em que se baseou o estudo, quanto na Carta de Direito dos Usuários do Brasil (27). Visando enfrentar esta realidade, sugere-se que seja feita uma ampla divulgação sobre o acesso dos usuários de serviços de saúde a suas informações de saúde, além de qualificar os profissionais de saúde, em particular, o grupo de médicos, que deveriam receber uma formação complementar de capacitação sobre os direitos dos usuários à informação, e os seus direitos a tomarem decisões.

O conhecimento dos direitos dos usuários é fundamental para o desenvolvimento de uma consciência democrática do cidadão e é o primeiro passo para diminuir as barreiras enfrentadas no exercício dos direitos. Deve buscar o alcance da humanização dos serviços de saúde, além de garantir a cidadania em saúde (34) Estudo (21) identificou a consciência dos usuários sobre seu direito à informação e revelou que, quanto maior a escolaridade, maior o entendimento e a conscientização sobre direitos.

Ainda neste contexto, outro estudo (19) abordou, também, a questão do conhecimento e consciência do usuário, referente ao usuário com câncer, sobre o direito de ser informado, sobre o dever do médico de informar o usuário sobre o diagnóstico e tratamento e a obrigação do médico de informar o usuário. Um estudo que buscou identificar os conflitos éticos vividos por oncologistas na comunicação de diagnósticos de câncer e, também, analisar os problemas desencadeados pelas más notícias, revelou que os principais conflitos éticos foram relacionados à justa adequação moral do emprego da verdade na comunicação, se esta é uma ação beneficente para o paciente, e ao manejo com a família na relação médico-paciente. Observou-se, também, que os problemas éticos desencadeados decorrem, principalmente, em relações paternalistas com interferência na autonomia do paciente (35) 
Em três estudos (18), (19), (31) foi evidenciada a questão paternalista dos médicos em informar apenas o que acreditam que seja importante para o usuário, limitando sua autonomia e poder de decisão. Neste sentido, essas informações limitam-se àquelas que os profissionais julgam ser necessárias e suficientes, nem sempre considerando e valorizando o que o usuário gostaria de saber sobre sua doença. Salientam ainda que a informação sonegada não decorre de má-fé, mas da postura paternalista que prevalece no setor da saúde, com a qual os profissionais têm a intenção de beneficiar o usuário, considerando o temor das conseqüências adversas à sua esfera psicológica (36).

No entanto, outro estudo (20) avaliou o conhecimento de mulheres sobre seus direitos numa maternidade. Observou-se, neste estudo, o respeito aos direitos das usuárias de serem informadas sobre seu estado de saúde, prognóstico, riscos oferecidos pelo tipo de parto, o conhecimento sobre os tipos de parto e sobre seu corpo. A maioria das mulheres respondentes que estavam na sala de parto não tiveram escolha quanto a vários destes direitos.

Entre as principais convenções da Assembleia Geral da Organização das Nações Unidas (ONU), que constituem parâmetros mínimos das ações estatais na promoção dos direitos humanos e na repressão às suas violações, está a Convenção Internacional para a Eliminação de todas as Formas de Discriminação contra a Mulher, adotada pela Resolução 34/180 da Assembleia Geral da ONU em 1979. É o documento mais importante sobre os direitos humanos das mulheres, pois trouxe o entendimento de que as mulheres são sujeitos de direito, e que os Estados tem obrigação legal de respeitar, proteger e implementar seus direitos (37). No contexto da maternidade, os parâmetros mínimos de direitos humanos, que vinculam saúde e proteção à maternidade, destacam-se pelo: (i) direito à vida; (ii) direito à liberdade e segurança pessoal; (iii) direito à saúde; (iv) direito à proteção na maternidade; e (v) direito à não-discriminação da mulher (37).

Assim, houve estudo (20) que observou que os direitos das usuárias numa sala de parto e maternidade não foram respeitados satisfatoriamente e, durante o período de hospitalização, as usuárias não foram informadas e não adquiriram qualquer conhecimento sobre seus direitos. As usuárias da maternidade, na maioria dos casos, foram receptoras passivas das informações prestadas. Algumas pessoas não têm informação porque não questionam os profissionais tornando-se apenas receptoras de informação e não conseguindo transformar essa informação em conhecimento. Muitas vezes, as mulheres 
não possuem informações suficientes desde o pré-natal, e chegam na sala de parto ou centro-cirúrgico não sabendo exatamente sobre o que se informar, o que dificulta 0 exercício de seus direitos enquanto usuária (38).

Outro ponto a ser ressaltado sobre o conhecimento do usuário sobre seu direito à informação deve-se ao direito de acessar seus registros médicos, ou ter acesso ao prontuário eletrônico do usuário. (24) Essa temática foi discutida a partir da legislação norueguesa, identificando que os usuários dos serviços de saúde solicitavam cópias de seus prontuários eletrônicos para ter controle sobre suas informações, por receio de que não houvesse transmissão adequada de dados entre instituições de saúde, abordando a questão da segurança e confidencialidade desses dados (24).

É ressaltado ainda que grande número de usuários têm usado seu conhecimento para ter seu direito de acesso respeitado, aumentando sua autonomia no que se refere à informação sobre sua saúde (24). Neste sentido, observa-se que solicitar a cópia de seu prontuário é representativo para o usuário que, consciente de seus direitos e livre-arbítrio, tem também a responsabilidade sobre esses dados (24). Estes dados se aproximam do conceito de autonomia, ou seja, a capacidade que a pessoa possui em autogovernar-se, de possuir liberdade de escolha e de agir em conformidade com sua própria vontade, de tomar decisões relacionadas à sua vida, à sua saúde, à sua integridade físico-psiquíca e às suas relações sociais (39).

O consentimento informado e a autonomia para menores de idade em países da Europa, e qual seria a idade ideal para que esses menores pudessem ter capacidade de decisão, consentir, recusar e opinar sobre procedimentos médicos e de sua saúde foram discutidos em estudo (25). Mesmo tratando-se de usuário menor de idade, deve haver uma explicação minuciosa e certificar-se de que este compreendeu a informação. Neste estudo, a "maioridade médica" foi analisada país a país, de acordo com a legislação vigente.

Nos países como Chipre, Grécia e Eslováquia, a idade para ter capacidade de decisão sobre sua saúde foi fixada em 18 anos. Na Dinamarca, Portugal, Eslovênia e Espanha optaram por fixar uma idade limite para a "maioridade médica". O país em que a maioridade foi a de menor idade foi Portugal: 14 anos, seguido de Dinamarca e Eslovênia: 15 anos, e Espanha: 16 anos. Em Portugal está sendo estudada a proposta de mudança de 14 para 16 anos. Na Espanha quando se trata de aborto, estudos clínicos e reprodução assistida a idade fixada para a maioridade é de 18 anos. A República Checa e Estônia 
optaram por um sistema flexível e analisam caso a caso de acordo com a idade e maturidade da criança. Na República Checa, também é levado em conta a seriedade da intervenção. Na Lituânia é fixada a idade de 16 anos, porém também há análise caso a caso quando a idade é inferior a 16 anos (25).

Frente a estas questões relacionadas ao conhecimento do usuários sobre o direito à informação, percebe-se a importância de possibilitar aos usuários dos serviços de saúde, condições para o reconhecimento dos direitos em relação à informação de suas enfermidades, opções de tratamentos e prognósticos, assim como o reconhecimento do direito de ter opiniões e de fazer escolhas em questões sobre sua saúde.

\section{Conhecimento de profissionais de saúde sobre o direito à informação do usuário}

Foram discutidas em estudos desta revisão questões sobre o nível de conhecimento dos profissionais de saúde sobre os direitos dos usuários estabelecidos na legislação (40); o consentimento informado como instrumento de informação na atenção secundária (41); o conhecimento dos médicos hospitalares e da atenção primária sobre os direitos do usuário (42); e as informações fornecidas pelos médicos da atenção primária para seus usuários nas distintas fases do processo assistencial e a análise da relação sócio-profissional com o trabalho médico (43).

Ao discutir a necessidade de informação e formação complementar em assuntos relacionados à legislação de saúde pelos profissionais de saúde, autores (40) ressaltam que grande número de usuários não entendem a informação recebida, sobre opções de tratamento ou complicações de saúde. O estudo indicou também que os profissionais que tinham tido algum treinamento sobre direitos dos usuários tinham melhor conhecimento sobre o direito à informação, enfatizando que a aplicação dos direitos do usuário não pode se concretizar sem o conhecimento. Ou seja, a informação não entendida, não mediada numa linguagem acessível ao usuário não gera conhecimento (40).

Houve outro estudo que observou sobre o direito dos usuários de acessar suas informações (28). Os resultados demonstraram a baixa taxa de observação deste direito, indicando a necessidade de capacitação das equipes, no sentido de informá-los quanto a importância do respeito ao direito à informação do usuário.

Nessa perspectiva, a questão da linguagem técnica ou de especialidade é explicitada na Carta de Direitos dos Usuários (27), que argumenta que a linguagem deve ser simples, 
aproximativa, inteligível, leal e respeitosa, ou seja, fornecida dentro de um padrão acessível à compreensão intelectual e cultural do usuário, pois quando indevidas e mal organizadas, resultam em baixo potencial informativo e em desinformação.

Há, portanto, uma diferença entre "informar" e "comunicar". Em relação à informação e comunicação sobre condições de saúde, o ato de informar está relacionado ao momento inicial da revelação de uma doença, do tratamento e do prognóstico. No entanto, as informações precisam estar inseridas na relação de comunicação entre o os profissionais de saúde com os usuários dos serviços de saúde (44).

O processo de comunicação exige mudança de atitude dos profissionais de saúde, com o objetivo de estabelecer uma relação empática e participativa, oferecendo ao paciente a possibilidade de decidir na escolha do tratamento. Dessa maneira, evidencia-se a responsabilidade dos profissionais de saúde na apropriação de uma postura reflexiva e ética, que contemple a adoção de novos conhecimentos e habilidades necessárias para a efetiva comunicação com os usuários dos serviços de saúde (45).

Questões sobre o consentimento informado foram discutidos em outro estudo (41), evidenciando a importância do consentimento no processo de tomada de decisão. O consentimento livre e esclarecido é uma condição indispensável da relação profissionalusuário. Trata-se de uma decisão voluntária, realizada por uma pessoa autônoma e capaz, tomada após um processo informativo e deliberativo, visando à aceitação de um tratamento específico ou experimentação, sabendo da sua natureza, das suas consequências e dos seus riscos (46). Expressa o respeito ao direito do paciente ou seus responsáveis legais de decidir, de modo esclarecido, a respeito de qualquer ato praticado para fins de diagnóstico e tratamento da doença (47).

Um estudo (42) mostrou que grande número de profissionais da área médica, tanto hospitalares quanto de cuidados primários, possuem lacunas no conhecimento sobre as leis relacionadas aos direitos dos usuários, inclusive sobre o direito do usuário à informação, podendo até sofrer penalidades legais ao revelar informações a familiares ou não respeitar o direito do usuário de não ser informado sobre o curso de sua doença.

Argumentou-se, em estudo (43), que a satisfação do profissional de saúde afeta a satisfação do usuário e que os profissionais insatisfeitos podem influenciar negativamente o comportamento do usuário como, por exemplo, o cumprimento do tratamento médico e a qualidade assistencial. Observou-se, também, que os profissionais que atendem menos 
usuários informam melhor e mais adequadamente esses usuários, do que os profissionais com sobrecarga de trabalho. Neste estudo, identificou-se que o dever de informar do médico não alcança níveis de eficácia suficientes. Há uma insatisfação com o trabalho nos médicos de família que influi negativamente no direito à informação do usuário.

Observa-se, portanto, a importância da capacitação dos profissionais de saúde para maior conhecimento a respeito do direito à informação dos usuários dos serviços de saúde, a fim de que os direitos possam ser reconhecido e exercidos.

\section{Considerações finais}

Verificou-se, nas categorias, a necessidade de capacitação de profissionais de saúde em relação ao direito dos usuários de serviços de saúde. Assim como no Brasil, as Cartas de Direitos dos Usuários aparecem como referência para os estudos envolvendo esta temática, evidenciando a preocupação com os direitos dos usuários nos países dos estudos primários selecionados como Bélgica, Espanha, Finlândia, Irã, Noruega, Polônia, Reino Unido e Turquia.

O fator "padrão subjetivo" de ter a informação adequada a cada usuário de serviço de saúde foi abordado, enfatizando-se a necessidade de se utilizar a linguagem acessível e evitar a linguagem de especialidade. Outro ponto que apareceu nos estudos foi 0 paternalismo existente na relação profissional-paciente, que deve ser evitado para que o usuário tenha toda a informação possível sobre sua saúde, e não apenas a que o profissional achar necessária.

Assim, a capacitação dos profissionais de saúde e, também, a educação em direito à saúde dos usuários dos serviços se mostram como estratégias concretas para se cumprir o direito à informação do usuário, melhorando a prática assistencial, as condições de saúde das pessoas e o exercício de seus direitos.

\section{Referências}

1. Marmelstein G. Curso de direitos fundamentais.São Paulo: Atlas, 2013.

2. Silva JAA. Curso de direito constitucional positivo. São Paulo: Malheiros Editores, 2014.

3. Bobbio N. A era dos direitos. Rio de Janeiro: Câmpus, 1992. 
4. Leite RAF. Direito à informação em saúde: análise do conhecimento do paciente acerca de seus direitos. Ribeirão Preto: Programa de Pós-Graduação em Enfermagem Pisquiátrica, Escola de Enfermagem de Ribeirão Preto, Universidade de São Paulo, 2010.

5. Smit JW. A informação na Ciência da Informação. InCID: Revista de Ciência da Informação e Documentação. 2012, 3(2):84-101.

6. Ventura CAA et al. Aliança da enfermagem com o usuário na defesa do SUS. Revista Brasileira de Enfermagem. 2012, 65(6):893-898.

7. Whittemore $\mathrm{R}$, Knafl $\mathrm{K}$. The integrative review: updated methodology. Journal of Advanced Nursing. 2005, 52 (5):546-53.

8. Briggs J. Reviewer's Manual. Adelaide (Australia): Royal Adelaide Hospital, 2014.

9. Stetler $\mathrm{C}$ et al. Utilization-focused integrative reviews in a nursing service. Applied Nursing Research. 1998, 11(4):195-206.

10. URSI ES. Prevenção de lesões de pele no perioperatório: revisão integrativa da literatura. Ribeirão Preto: Programa de Pós-Graduação em Enfermagem Fundamental, Escola de Enfermagem de Ribeirão Preto, Universidade de São Paulo, 2005.

11. Ganong L. Integrative reviews of nursing research. Research in Nursing \& Health. 198, $10(1): 1-11$.

12. Melnyk BM, Fineout-Overholt E. Making the case for evidence-based practice and cultivationg a spirit of inquiry. In: MELNYK BM. Evidence-based practice in nursing and healthcare: a guide to best practice. Philadelphia : Lippincott Williams \& Wilkins, 2011,(1)324.

13. OMS. Organização Mundial da Saúde. Constituição da Organização Mundial da Saúde, 1946. Disponível em: http://www.direitoshumanos.usp.br/index.php/OMS-

Organiza\%C3\%A7\%C3\%A3o-Mundial-da-Sa\%C3\%BAde/constituicao-da-organizacaomundial-da-saude-omswho.html. Acesso em 15.2.2017.

14. Ayres JRCM. O cuidado, os modos de ser (do) humano e as práticas de saúde. Saúde e Sociedade. 2004,13(3):16-29.

15. Humenhuk $\mathrm{H}$. O direito à saúde no Brasil e a teoria dos direitos fundamentais. Jus Navigandi. 2004, 8(227).

16. Sarlet IW. A eficácia dos direitos fundamentais. Porto Alegre: Livraria do Advogado, 2012.

17. Conselho Nacional de Secretários de Saúde. SUS: avanços e desafios. Brasília: CONASS, 2006. 
18. Devroey $D$ et al. The perception of patients' rights among Belgian population. Central European Journal of Public Health. 2013, 21(2):109-117.

19. Erer S, Atici E, Erdemir AD. The views of cancer patients on patient rights in the context of information and autonomy. Journal of Medical Ethics. 2008, 34 ():384-388.

20. Leszczynska $\mathrm{K}$ et al. Obeying patient's rights on the basis of maternity ward. Roczniki Akademii Medycznej w Białymstoku. 2005, 50,Suppl 1:70-73.

21. Mastaneh Z, Mouseli L. Patients' awareness of their rights: insight from a developing country. International Journal of Health Policy and Management. 2013, 1(2):143-146.

22. Kaya $E$ et al. The effect of giving detailed information about intravenous radiopharmaceutical administration on the anxiety level of patients who request more information. Annals of Nuclear Medicine. 2010, 24(2):67-76.

23. Pérez-Cárceles MD et al. Is the right to information fulfilled in an emergency department? Patients' perceptions of the care provided. Journal of Evaluation in Clinical Practice, 2010, 16(3):456-463.

24. Wibe $\mathrm{T}$ et al. Why do people want a paper copy of their electronic patient record? Studies in Health Technology and Informatics. 2010, 160(1):676-680.

25. Stultiens $\mathrm{L}$ et al. Minors and informed consent: a comparative approach. European Journal of Health Law. 2007, 14(1):21-46.

26. Brasil. Lei 8.080 de 19 de setembro de 1990. Dispõe sobre as condições para a promoção, proteção e recuperação da saúde, a organização e o funcionamento dos serviços correspondentes e dá outras providências. Disponível em:

http://www.planalto.gov.br/ccivil 03/Leis/L8080.htm Acesso em 15.12.2017.

27. Ministério da Saúde. Carta dos direitos dos usuários da saúde. Brasília: Ministério da Saúde, 2011.

28. Parsapoor A et al. Necessity of Observing Patient's Rights: a survey on the attitudes of patients, nurses and physicians. Journal of Medical Ethics and History of Medicine. 2012, 5: 2.

29. Fortes PAC. Reflexões sobre a bioética e o consentimento esclarecido. Bioética. 1994, 2(2):129-135.

30. Biondo-Simões MLP et al. Compreensão do termo de consentimento informado. Revista do Colégio Brasileiro de Cirurgiões. 2007, 34(3):183-188.

31. Perez-CarceleS MD et al. Derecho de información de los pacientes: influencia de las características socioprofesionales em atención. Atención Primaria 2006, 37 (2): 69-74.

32. Coelho LCD et al. Conflitos éticos na revelação de informações - Parte II. Ciência Cuidado e Saúde. 2008, 7(1):73-82. 
33. Engelhardt H. Tristram. Fundamentos de bioética. São Paulo: Loyola, 2008.

34. Gauderer EC. Os direitos do paciente. Rio de Janeiro: Record; 1998.

35. Geovanini F, Braz M. Conflitos éticos na comunicação de más notícias em oncologia. Revista Bioética. 2013, 21(3):455-62.

36. Holm s. What is wrong with compliance? Journal of Medical Ethics. 1993, 19:108-110.

37. Piovesan Flávia. Os direitos humanos da mulher na ordem internacional. In:

(Org.). Temas de direitos humanos. 2.ed. São Paulo: Max Limonad, 2003ํ/

38. Carmo DRB. Possibilidade de manifestação da autonomia do paciente internado em um hospital universitário. Ribeirão Preto: Programa de Pós-Graduação em Enfermagem, Escola de Enfermagem de Ribeirão Preto, Universidade de São Paulo; 2002.

39. Beauchamp T, Childress, J. Princípios de ética biomédica. São Paulo: Edições Loyola; 2002.

40. Inen $S$ et al. Knowledge about patients' rights among professionals in public health care in Finland. Scandinavian Journal of Caring Sciences. 2012, 26(3):436-448.

41. Heywood R, Macaskill A, QWId consent in hospital practice: health professionals' perspectives and legal reflections. Medical Law Review. 2010, 18(2):152-184.

42. MIRA JJ et al. Derechos de los pacientes: algo más que uma cuéstion de actitud. Gaceta Sanitaria. 2010, 24:247-250.

43. Perez-Carceles MD et al. Observance of Patient's Rights: a survey on the views of patients, nurses, and physicians. Journal of Medical Ethics and History of Medicine. 2012 5: 5.

44. Trindade ES et al. O médico frente ao diagnóstico e prognóstico do câncer avançado. Revista da Associação Médica Brasileira. 2007, 53(1):68-74.

45. Pessini L, Barchifontaine C. Problemas atuais de bioética. São Paulo (SP): Loyola; 2002.

47. Hirschheimer MR et al. Consentimento informado no atendimento pediátrico. Revista Paulista de Pediatria. 2010, 28 (2):128-33. 